\title{
Sensitive Periods for Visual Calibration of the Auditory Space Map in the Barn Owl Optic Tectum
}

\author{
Michael S. Brainard ${ }^{1}$ and Eric I. Knudsen ${ }^{2}$ \\ ${ }^{1}$ Keck Center for Integrative Neuroscience, Departments of Physiology and Psychiatry, University of California, San \\ Francisco, San Francisco, California 94143-0444, and 2Department of Neurobiology, Stanford University School of \\ Medicine, Stanford, California 94305-5125
}

Previous studies have identified sensitive periods for the developing barn owl during which visual experience has a powerful influence on the calibration of sound localization behavior. Here we investigated neural correlates of these sensitive periods by assessing developmental changes in the capacity of visual experience to alter the map of auditory space in the optic tectum of the barn owl. We used two manipulations. (1) We equipped owls with prismatic spectacles that optically displaced the visual field by $23^{\circ}$ to the left or right, and (2) we restored normal vision to prism-reared owls that had been raised wearing prisms. In agreement with previous behavioral experiments, we found that the capacity of abnormal visual experience to shift the tectal auditory space map was restricted to an early sensitive period. However, this period extended until later in life $(\sim 200 \mathrm{~d})$ than described previously in behavioral studies ( $\sim 70 \mathrm{~d})$. Furthermore, unlike the previous behavioral studies that found that the capacity to recover normal sound localization after restoration of normal vision was lost at $\sim 200$ $\mathrm{d}$ of age, we found that the capacity to recover a normal auditory space map was never lost. Finally, we were able to reconcile the behaviorally and neurophysiologically defined sensitive periods by taking into account differences in the richness of the environment in the two sets of experiments. We repeated the behavioral experiments and found that when owls were housed in a rich environment, the capacity to adjust sound localization away from normal extended to later in life, whereas the capacity to recover to normal was never lost. Conversely, when owls were housed in an impoverished environment, the capacity to recover a normal auditory space map was restricted to a period ending at $\sim 200 \mathrm{~d}$ of age. The results demonstrate that the timing and even the existence of sensitive periods for plasticity of a neural circuit and associated behavior can depend on multiple factors, including (1) the nature of the adjustment demanded of the system and (2) the richness of the sensory and social environment in which the plasticity is studied.

Key words: sensitive period; critical period; auditory plasticity; sound localization; auditory map; space map; optic tectum; superior colliculus; barn owl; Tyto alba
Many behaviors are shaped profoundly by experience during restricted "sensitive" or "critical" periods of development. Examples include imprinting in birds and mammals (Immelmann, 1972; Leiderman, 1981; Bolhuis, 1991; Hudson, 1993), vocal learning in song birds (Marler, 1970; Eales, 1985, 1987; Baptista and Petrinovich, 1986; Clayton, 1989), and language learning in humans (Needleman, 1977; Ruben and Rapin, 1980; Clarkson et al., 1989; Kuhl, 1991). In this study, we investigated neurophysiological correlates of sensitive periods in the development of sound localization in barn owls.

Previous studies have shown that sound localization behavior in barn owls is shaped by early experience. For example, when an owl is raised wearing prismatic spectacles that displace the apparent locations of auditory stimuli along the horizon, the owl learns to adjust its auditory orienting response according to the optical displacement of the visual field so that it sees the source

\footnotetext{
Received Dec. 12, 1997; revised March 2, 1998; accepted March 4, 1998.

This work was supported by National Institutes of Health Grants RO1 DC 00155 and T32 NS 07158. M.S.B. is a Burroughs Wellcome Fund Fellow of the Life Sciences Research Foundation. We thank Phyllis Knudsen for her technical assistance throughout this project and especially for her help in training and testing owls for behavioral experiments.

Correspondence should be addressed to Michael S. Brainard, Department of Physiology, Box 0444, University of California, San Francisco, 513 Parnassus Avenue, Room 762-S, San Francisco, CA 94143-0444.

Copyright (C) 1998 Society for Neuroscience $\quad 0270-6474 / 98 / 183929-14 \$ 05.00 / 0$
}

of the auditory stimulus through the prisms (Knudsen and Knudsen, 1989a). Thus, owls learn associations between values of sound localization cues and the locations in space that produce them based, in part, on visual experience.

The ability of abnormal visual experience to alter sound localization behavior is developmentally regulated. In one previously published study (Knudsen and Knudsen, 1990), owls equipped with prismatic spectacles within the first month of life exhibited large adaptive shifts in auditory orienting behavior, whereas owls equipped with prisms as adults did not. The capacity of abnormal vision to alter sound localization declined to adult levels by 70-100 d of age. Therefore, the first few months of life were referred to as a sensitive period during which sound localization could be altered in response to abnormal visual experience.

In the same study, it was also shown that the restoration of normal vision to owls that were raised wearing prisms led to full recovery of accurate sound localization in animals younger than $\sim 200 \mathrm{~d}$ old, an age that just precedes sexual maturation. In contrast, owls that continued to view the world through prisms until adulthood failed to recover accurate sound localization after prism removal. Thus, the juvenile period, ending at $\sim 200 \mathrm{~d}$, was referred to as a critical period during which experience with normal vision was required for the acquisition of normal sound localization.

Here we investigated the developmental regulation of plasticity 
in an auditory pathway that contributes to sound localization behavior. The optic tectum in the barn owl contains a multimodal map of space consisting of neurons that respond both to auditory and to visual stimuli located in restricted regions of space, or receptive fields (Knudsen, 1982). The auditory and visual receptive fields (VRFs) of bimodal tectal neurons are mutually aligned, because these neurons are tuned to the values of interaural time difference (ITD) and interaural level difference (ILD) that correspond to sound stimuli located at the center of their visual receptive fields (Olsen et al., 1989). Analogous to its effects on sound localization behavior, prism-rearing shifts the values of ITD and ILD to which tectal neurons are tuned so that prism experience causes auditory receptive fields to realign with prismatically displaced VRFs, thereby bringing the auditory and (optically shifted) visual maps of space into register (Knudsen and Brainard, 1991; Brainard and Knudsen, 1993).

In this study we show that, like sound localization behavior, the map of auditory space in the optic tectum is most susceptible to calibration by visual experience during restricted periods of development. Furthermore, we demonstrate that the durations of these periods depend crucially on the richness of the animal's environment.

Data from some of these owls have been published previously (Knudsen and Brainard, 1991; Brainard and Knudsen, 1993, 1995).

\section{MATERIALS AND METHODS}

A total of 62 barn owls (Tyto alba) were used for this study: 39 were used for electrophysiological measurements of plasticity in the optic tectum (see Table 1), and three were used for measurements of plasticity of auditory orienting behavior. The remaining owls provided control data on the normal properties of the tectal space map.

Prisms. Forty-two owls were exposed to a chronic, optical displacement of the visual field for various periods of time. In every case, the visual field was displaced horizontally, $23^{\circ}$ either to the right or left, with Fresnel prismatic lenses (VisionCare/3M) mounted in spectacle frames. Because barn owls cannot deviate the eyes in the head to compensate for the prisms (Steinbach and Money, 1973; Knudsen and Knudsen, 1989b), the spectacles exposed the owls to a systematically altered correspondence between auditory cues, specifically ITD, and the azimuthal location of stimulus sources in the visual field.

For owls $<60 \mathrm{~d}$ old, spectacle frames were sutured to the scalp. Lenses were cleaned daily and adjusted as needed to maintain alignment with the visual axes. Beyond $60 \mathrm{~d}$ of age, after the skull had reached adult size and hardened, permanent spectacles were attached to a plate that was cemented to the skull, and the prisms were cleaned twice per week.

Housing conditions. Owls were either collected from the wild or reared in our breeding aviaries. Owls that were used for neurophysiological studies were separated from their parents between hatching and $\sim 20 \mathrm{~d}$ of age and were maintained in groups of two to four in small nest boxes that were similar to their natural environment. In addition to interactions with each other, the primary stimulation for these owls was provided by care givers who fed the owls and cleaned the cages daily. Owls that were used for behavioral studies were always housed individually and received more handling by humans to keep them tame.

As owls became capable of feeding themselves and required less care, at 30-40 d of age, they were transferred to small cages where they were typically housed individually. The small cages were made of stainless steel sheets and measured $78 \mathrm{~cm}$ wide, $60 \mathrm{~cm}$ deep, and $60 \mathrm{~cm}$ high. They contained one perch and two large windows. The cages were placed on racks so that the windows faced each other, allowing the owls to see and hear each other as well as the animal care providers.

When owls became capable of flight, at 60-70 d of age, they were normally transferred to large aviaries. These aviaries were made of cyclone fencing lined with nylon screen. The cages were of three sizes. The largest aviary measured $2.4 \mathrm{~m}$ wide, $6.0 \mathrm{~m}$ long, and $2.4 \mathrm{~m}$ high and contained six nesting boxes and numerous perches. This aviary typically contained 10 owls at one time, and most of the owls in this study were housed in this aviary. A smaller aviary measured $1.5 \mathrm{~m}$ wide, $2.4 \mathrm{~m}$ long, and $2.4 \mathrm{~m}$ high and contained one nesting box and two perches. This room typically contained four owls at one time. A third flight room was used to house the tame owls used in the behavioral experiments. These birds had to be kept separate from other birds to control their food intake. This room measured $1.0 \mathrm{~m}$ wide, $2.4 \mathrm{~m}$ long, and $2.4 \mathrm{~m}$ high and was separated from a neighboring flight room, which contained wild owls, by a wire mesh fence. The tame birds could easily see and hear the owls in the neighboring room.

In some experiments, as explicitly noted in Results, owls were returned to small cages to study the influence of housing conditions on plasticity. This was done to match the conditions of the current study with those of a previous behavioral study in which the small cages were used exclusively (Knudsen and Knudsen, 1990).

Electrophysiology. The owls that were used in the electrophysiological study were prepared for recording at $\sim 2$ months of age. During surgery, the owls were anesthetized with halothane $(1 \%)$ in a mixture of oxygen and nitrous oxide $(55: 45)$, and incisions were infiltrated with lidocaine hydrochloride. Two metal plates, one for holding the head during recording experiments and one for mounting the spectacle frames, were cemented to the skull. Craniotomies were made over the optic lobes, and in some cases stainless steel recording chambers were cemented into the craniotomies. The surface of the brain was suffused with a sterile antibiotic solution and temporarily sealed either with dental acrylic or with a stainless steel plug. Owls were allowed to recover for at least 1 week before electrophysiological recordings were begun.

On the day of an experiment, the owl was anesthetized with halothane and nitrous oxide (as above) or ketamine hydrochloride $(5-10 \mathrm{mg} / \mathrm{kg}$, i.m.) and diazepam $(0.5-1.0 \mathrm{mg} / \mathrm{kg}, \mathrm{i} . \mathrm{m}$.). The craniotomies were opened either by removing the dental acrylic or unscrewing the plug, as appropriate, and the dura was retracted. The owl was wrapped in a soft leather jacket and suspended in a sound isolation chamber. The head was secured relative to a stereotaxic microdrive and aligned using retinal landmarks so that the visual axes were horizontal. Because there were no fresh incisions or pressure points, the owl was allowed to recover from the initial anesthesia, and subsequent anesthesia was administered only if the owl did not rest quietly. To minimize the influence of anesthesia on unit responses, we did not collect data during the 40 min after ketamine administration or the $15 \mathrm{~min}$ after halothane administration.

Multi-unit extracellular recordings were made with lacquer-coated tungsten microelectrodes (1-3 M $\Omega$ at $1 \mathrm{kHz})$. A level discriminator was used to isolate units for measurement, and the timing of action potentials was stored on a computer. At the end of a recording session the craniotomy was sealed, fluids were administered intramuscularly, and the owl was monitored in an observation cage until it was fully recovered.

Chronic recording electrodes (made as described above) were used to measure repeatedly the ITD tuning at single tectal sites in four owls. Electrodes were initially implanted under microdrive control while unit responses were recorded. Typically, one electrode was implanted in each tectum, and each electrode was positioned at a location where vigorous multi-unit responses could be elicited by both auditory and visual stimuli. Electrodes were fixed in place by securing the shaft of the electrode to the skull with dental acrylic. The end of the electrode was clipped to a length of $\sim 1 \mathrm{~cm}$, bent parallel to the skull, and secured to the skull with more acrylic so that only a short, protected recording lead remained accessible. Responses to auditory and visual stimuli were measured repeatedly over periods ranging from several weeks to several months after implantation. The locations of recording sites remained constant as judged from the locations of VRFs, which never varied across recording sessions by more than $2^{\circ}$ in azimuth, approximately equal to the precision with which they could be measured.

Auditory measurements. Unit tuning for ITD was measured by delivering computer-generated sounds via matched earphones (Knowles, ED1941 coupled to damping assembly BF-1743) placed in the external ear canals at a distance of $\sim 5 \mathrm{~mm}$ from the ear drum. All stimuli were 50 msec in duration, with rise-fall times of $0 \mathrm{msec}$, and had broadband spectra that were high-pass filtered at $4 \mathrm{kHz}$ to minimize sound propagation through the interaural canal of the owl (Moiseff and Konishi, 1981; Olsen et al., 1989).

ITD tuning was measured in increments of $10-15 \mu \mathrm{sec}$ over a range of $100-200 \mu$ sec. Each value of ITD was presented 10-20 times in a randomized, interleaved order. Measurements were made at an average binaural level of 20-30 dB above unit threshold, and the ILD was held constant at a near optimal value for each site. Unit responses to stimuli were quantified as the number of spikes occurring in the $100 \mathrm{msec}$ after stimulus onset minus the number of spikes occurring in the $100 \mathrm{msec}$ before the stimulus (baseline). The width of ITD tuning was defined as the difference between the most left-ear leading and right-ear leading 
values of ITD for which the interpolated response exceeded $50 \%$ of the maximum response. Best ITD was defined as the midpoint of this range. For some sites, ITD tuning curves were double-peaked so that this range included intermediate values of ITD for which responses were $<50 \%$ of the maximum response, as has been observed previously (Brainard and Knudsen, 1995). Negative ITDs indicate left-ear leading values.

Visual measurements. VRFs were measured by projecting dark or light bars onto a calibrated translucent hemisphere, $57 \mathrm{~cm}$ in radius, placed in front of the owl. VRF location is represented by the center of the receptive field and is reported in a double-pole coordinate system (Knudsen, 1982) in which azimuth indicates degrees right (R) or left (L) of the midsagittal plane and elevation indicates degrees above $(+)$ or below $(-)$ the visual (horizontal) plane, with all angles measured from the center of the head.

Sampling of the optic tectum. The shift in the auditory space map that was induced by prism experience was not uniform across the tectum. The largest shift always occurred in the region of the tectum that represented the optically displaced portion of the visual field (Knudsen and Brainard, 1991; Brainard and Knudsen, 1993). Because of the topographic variation in the amount of shift in the auditory map, we sampled only a restricted zone of the rostral tectum, which represented frontal space. For owls $\operatorname{Pr} 4$, Pr5, Pr6, Pr14, Pr18, Pr30, Pr31, and E65, the sample zone was the visual representation of $\mathrm{L} 15^{\circ}$ to $\mathrm{R} 15^{\circ}$ and $0^{\circ}$ to $-25^{\circ}$; for all of the other owls, the sample zone was $\mathrm{L} 15^{\circ}$ to $\mathrm{R} 15^{\circ}$ and $+15^{\circ}$ to $-20^{\circ}$. The values reported here reflect only the shifts in the auditory space map that occurred within this rostral zone.

Within the zone of the tectum that was sampled, measurements were separated by a minimum interval of $400 \mu \mathrm{m}$ along each electrode penetration, and electrode penetrations were spaced at a minimum interval of $500 \mu \mathrm{m}$. This assured that a large portion of the rostral zone was sampled and that each measurement reflected auditory tuning in a different portion of the space map.

Assessment of the representation of ITD in the optic tectum. In the tecta of normal owls, best ITDs vary systematically with the azimuths of VRFs (Olsen et al., 1989). Because the locations of VRFs are not altered by prism-rearing (Brainard and Knudsen, 1993), the degree of prisminduced shift in ITD tuning could be quantified by comparing the measured value of best ITD with the value that was predicted from the normal relationship between best ITD and VRF azimuth (measured without prisms): predicted best ITD $=$ VRF az $\times 2.5 \mu \mathrm{sec} / \mathrm{deg}$ (Brainard and Knudsen, 1993).

Shifts in the representation of ITD were assessed in two ways. First, shifts in best ITD values were quantified as the difference between the measured best ITD and the predicted normal best ITD for each site, averaged across all sites in a given recording session. Second, consistent changes in tuning curve shape were revealed by constructing population ITD tuning curves. Population tuning curves were derived from the sample of ITD tuning curves measured in a single recording session. To combine tuning curves representing different sites, the ITD tuning curve for each site was normalized to the maximum response. Then, the values of ITD that were tested were transformed into values of ITD relative to the predicted normal best ITD for that site, based on the VRF of the site. The normalized responses for standard values of ITD (either 10 or 15 $\mu \mathrm{sec}$ intervals) relative to predicted normal best ITD were interpolated. These interpolated responses were then averaged across all sites for each standard value of ITD.

Behavioral training and testing. The behavioral methods used in this study were the same as those used in a previous study (Knudsen and Knudsen, 1990). Auditory orientation accuracy was quantified by comparing the way the owls oriented the head (and therefore eyes) to auditory versus visual stimuli: a normal owl orients the head identically to both kinds of stimuli. Behavioral tests were conducted with the owl perched in a darkened sound isolation chamber (IAC 404A). Auditory stimuli were generated by a movable $6 \mathrm{~cm}$ loudspeaker and consisted of repetitive noise bursts of variable amplitude, duration, and repetition rate. Visual stimuli consisted of a modulated glow from a light-emitting diode that was centered in the speaker cone. The loudspeaker and photodiode were attached to a semicircular track that moved around the owl by remote control (Knudsen and Knudsen, 1989a).

Head orientations were monitored using a search coil system (C-N-C Engineering). A search coil was attached to the head by a clip cemented to the skull. The search coil system was calibrated before each test session. The precision of the system was $\pm 0.1^{\circ}$ in the frontal area that was sampled most heavily and fell to approximately $\pm 1.0^{\circ}$ at the most extreme positions tested.
The owl was placed on a perch in the center of the sound isolation chamber. The prisms were removed, the search coil was attached to the head, and the lights were extinguished. The loudspeaker-photodiode was moved to a random location in front of the owl. Then, either the auditory or the visual stimulus was presented. If the animal did not respond, the stimulus was turned off and a waiting period of $\sim 30 \mathrm{sec}$ ensued. Typically, however, the animal responded immediately with a quick head movement and a sustained fixation. The coordinates of the orientation response were recorded, a reward light was activated, and a food reward was delivered. The reward criteria were that the owl turn its head crisply and fixate on a point during the stimulus. After every trial, the stimulus source was moved to a new, random location. Because auditory and visual stimuli were presented independently and because the accuracy of head orientation relative to the target was not a criterion for reward, the test paradigm did not itself modify orientation behavior, but instead simply assessed the effect that experience outside of the test chamber had on orientation behavior.

A test session consisted of 10-25 responses to the auditory stimulus and a similar number of responses to the visual stimulus. Each response was quantified as the search coil reading minus the position of the stimulus source to yield coil orientation relative to source location. Mean response and SD were calculated separately for the auditory and visual responses. The difference between the mean auditory and the mean visual response is reported as the auditory orientation error.

\section{RESULTS}

\section{The capacity for altered visual experience to shift the auditory map of space declines with age}

To assess developmental changes in the capacity for altered visual experience to shape the tectal map of auditory space, 39 owls were equipped with prismatic spectacles at ages ranging from $13 \mathrm{~d}$ to $>2$ years (Table 1). Subsequent changes in ITD tuning were measured using chronic recordings from single tectal sites or acute recordings from multiple tectal sites.

In young owls, altered visual experience caused large adaptive changes in tectal tuning for ITD. Figure 1 shows an example of visually guided changes in ITD tuning for an owl (Pr18) that was raised normally until $88 \mathrm{~d}$ of age and then was equipped with prismatic spectacles that shifted the visual field to the right by $23^{\circ}$ $\left(\mathrm{R} 23^{\circ}\right)$. Before prisms were mounted, auditory and visual tuning were characterized at 13 sites across the tectal space map. Figure $1 A$ shows the ITD tuning measured at a site in the rostral tectum where the VRF was located directly in front of the owl [L1 ${ }^{\circ}$ azimuth (az), $-2^{\circ}$ elevation (el)]. The ITD tuning curve for the site $(\bigcirc)$ was narrow and symmetric with a best ITD of $1 \mu \mathrm{sec}$ left-ear leading. This value is close to the normal value predicted for this site (Fig. 1A, open arrow) based on the VRF location of the site (see Materials and Methods). Across all recording sites from this owl, there was a systematic progression of best ITD with VRF location (Fig. 1B, O). As VRF azimuths moved from left to right, best ITDs moved from more left-ear leading to more right-ear leading values. The data from this owl, before prism experience, closely approximated the relationship between best ITD and VRF azimuth (Fig. 1B, dashed line) determined previously for a large number of tectal units recorded from normally reared owls (Brainard and Knudsen, 1993).

After Pr18 was equipped with $\mathrm{R} 23^{\circ}$ prismatic spectacles at $88 \mathrm{~d}$ of age, the tectal representation of ITD began to change. An example of ITD tuning measured after $28 \mathrm{~d}$ of prism experience is shown in Figure $1 A(\mathbf{)})$ for a site in the rostral tectum where the VRF was located directly in front of the owl $\left(\mathrm{L}^{\circ} \mathrm{az}, 0^{\circ} \mathrm{el}\right)$. Like the tuning curve measured before prism experience, this tuning curve was narrow and symmetric. However, the best ITD was $46 \mu$ sec left-ear leading. This value is well outside the normal range for units with frontally located VRFs and is shifted toward the value of ITD that was produced by sound stimuli located in 


\begin{tabular}{|c|c|c|c|c|c|c|c|c|c|}
\hline \multirow[b]{2}{*}{ Owl I.D. } & \multirow{2}{*}{$\begin{array}{l}\text { Prism shift } \\
\text { (left or right) }\end{array}$} & \multicolumn{4}{|l|}{ Shift } & \multicolumn{4}{|l|}{ Recovery } \\
\hline & & Prisms on (days old) & $\operatorname{Mean}^{a}(\mu \mathrm{sec}$ ITD $)$ & SD & $n$ & Prisms off (days old) & $\operatorname{Mean}^{a}(\mu \sec$ ITD $)$ & $\mathrm{SD}$ & $n$ \\
\hline 13 & $\mathrm{~L}$ & 13 & 51 & 12 & 22 & 1175 & 5 & 5 & 16 \\
\hline 33 & $\mathrm{R}$ & 14 & 32 & 14 & 11 & & & & \\
\hline Pr4 & $\mathrm{R}$ & $15^{b}$ & 41 & 6 & 17 & 108 & 2 & 7 & 14 \\
\hline $\operatorname{Pr} 5$ & $\mathrm{R}$ & $15^{b}$ & 47 & 6 & 19 & 228 & 0 & 7 & 16 \\
\hline Pr6 & $\mathrm{R}$ & $15^{b}$ & 31 & 6 & 17 & 169 & 1 & 6 & 18 \\
\hline 29 & $\mathrm{~L}$ & 16 & 56 & 20 & 17 & 602 & 6 & 8 & 10 \\
\hline 90 & $\mathrm{R}$ & 16 & 39 & 19 & 5 & & & & \\
\hline 21 & $\mathrm{~L}$ & 17 & $68^{c}$ & & 2 & 159 & $1^{c}$ & & 2 \\
\hline 95 & $\mathrm{~L}$ & 17 & 27 & 24 & 9 & & & & \\
\hline 85 & $\mathrm{R}$ & 17 & 48 & 27 & 33 & & & & \\
\hline 25 & $\mathrm{R}$ & 18 & $48^{c}$ & & 2 & 161 & $4^{c}$ & & 1 \\
\hline 92 & $\mathrm{~L}$ & 18 & $32^{c}$ & & 2 & & & & \\
\hline 17 & $\mathrm{R}$ & 18 & 50 & 16 & 19 & 1256 & 7 & 6 & 22 \\
\hline 390 & $\mathrm{~L}$ & 18 & 54 & 13 & 30 & & & & \\
\hline 397 & $\mathrm{~L}$ & 19 & 34 & 9 & 17 & 246 & 6 & 6 & 13 \\
\hline 94 & $\mathrm{R}$ & 19 & 43 & 9 & 5 & 223 & 4 & 5 & 9 \\
\hline 398 & $\mathrm{R}$ & 20 & 37 & 9 & 16 & & & & \\
\hline 86 & $\mathrm{R}$ & 21 & 37 & 11 & 46 & & & & \\
\hline 91 & $\mathrm{~L}$ & 50 & 43 & 19 & 25 & & & & \\
\hline 30 & $\mathrm{~L}$ & 60 & 56 & 13 & 10 & & & & \\
\hline 45 & $\mathrm{~L}$ & 60 & 66 & 14 & 20 & & & & \\
\hline 46 & $\mathrm{~L}$ & 60 & 54 & 15 & 17 & & & & \\
\hline 64 & $\mathrm{~L}$ & 61 & 58 & 16 & 10 & & & & \\
\hline 24 & $\mathrm{R}$ & 63 & 30 & 12 & 10 & & & & \\
\hline 28 & $\mathrm{R}$ & 64 & 47 & 9 & 10 & 254 & $5^{c}$ & & 2 \\
\hline Mal & $\mathrm{L}$ & 65 & 26 & 8 & 19 & & & & \\
\hline 98 & $\mathrm{~L}$ & 67 & 58 & 7 & 19 & & & & \\
\hline 37 & $\mathrm{~L}$ & 69 & 43 & 10 & 6 & & & & \\
\hline 70 & $\mathrm{R}$ & 70 & 34 & 8 & 38 & & & & \\
\hline $\operatorname{Pr} 18$ & $\mathrm{R}$ & 88 & 41 & 6 & 13 & & & & \\
\hline $\operatorname{Pr} 18^{d}$ & $\mathrm{~L}$ & 124 & 51 & 14 & 14 & & & & \\
\hline E65 & $\mathrm{R}$ & 135 & 39 & 15 & 16 & & & & \\
\hline Ike & $\mathrm{R}$ & 160 & $41^{c}$ & & 3 & & & & \\
\hline Pr31 & $\mathrm{L}$ & 197 & 23 & 29 & 17 & & & & \\
\hline Pr14 & $\mathrm{R}$ & 200 & 1 & 5 & 14 & & & & \\
\hline Pr30 & $\mathrm{R}$ & 230 & 9 & 5 & 17 & & & & \\
\hline $\operatorname{Ad} 222$ & $\mathrm{R}$ & $>365$ & 4 & 3 & 15 & & & & \\
\hline Ad483 & $\mathrm{R}$ & $>365$ & 1 & 13 & 9 & & & & \\
\hline Ad831 & $\mathrm{L}$ & $>365$ & 6 & 7 & 13 & & & & \\
\hline $\operatorname{Ad} 712$ & $\mathrm{~L}$ & $>730$ & 4 & 4 & 14 & & & & \\
\hline
\end{tabular}

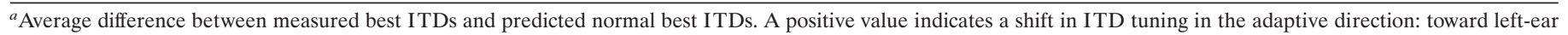
leading ITDs for right-shifting prisms and toward right-ear leading ITDs for left-shifting prisms.

${ }^{b}$ Raised with hoods that prevented vision from 10 to $15 \mathrm{~d}$ old.

${ }^{c}$ Measurement based on chronic recordings.

${ }^{d}$ Had previous experience with $\mathrm{R} 23^{\circ}$ prisms.
}

the optically displaced VRF of the site (Fig. 1 A, filled arrow). In this sense, the ITD tuning at the site had been shifted in the adaptive direction. Such adaptive shifts in ITD tuning were observed across the sampled portion of the tectum. Figure $1 B(\mathbf{O})$ shows the relationship between best ITD and VRF azimuth for 13 units recorded from this owl after $28 \mathrm{~d}$ of prism experience. Although there was a systematic relationship between best ITD and VRF azimuth, the relationship was displaced relative to normal, indicating that the altered visual experience of the owl had shifted the tectal map of ITD.

To quantify the magnitude of shift in the representation of
ITD, we calculated the difference between the measured value of best ITD at each site and the value predicted from the normal relationship between best ITD and VRF azimuth (Fig. $1 B$, dashed line) (Brainard and Knudsen, 1993). For Pr18, the distribution of differences before prisms were mounted (Fig. 1C, open bars) had a mean value of $1 \mu$ sec right-ear leading, confirming that the representation of ITD in the tectum of this owl was normal before altered visual experience. The distribution of differences after experience with $\mathrm{R} 23^{\circ}$ prisms (Fig. $1 C$, filled bars) had a mean value of $41 \mu \mathrm{sec}$ left-ear leading, indicating a large adaptive shift in ITD tuning. 


\section{Owl Pr18 \\ $\mathrm{R}^{2} 3^{\circ}$ prisms on at 88 days}
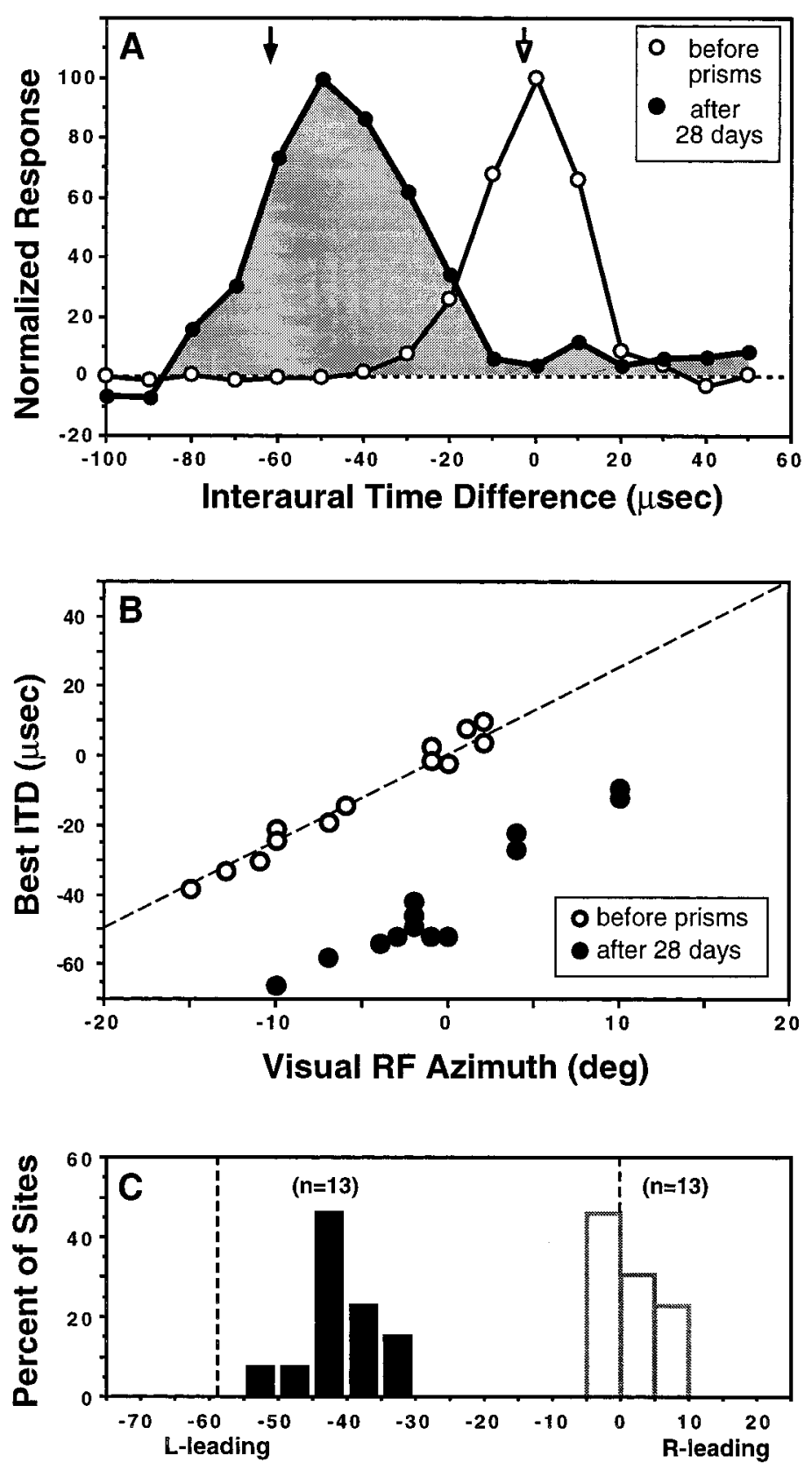

Best ITD Relative to Predicted ( $\mu \mathrm{sec})$

\section{Owl Ad222 \\ $\mathrm{R}^{\circ} 3^{\circ}$ prisms on at $>365$ days of age}
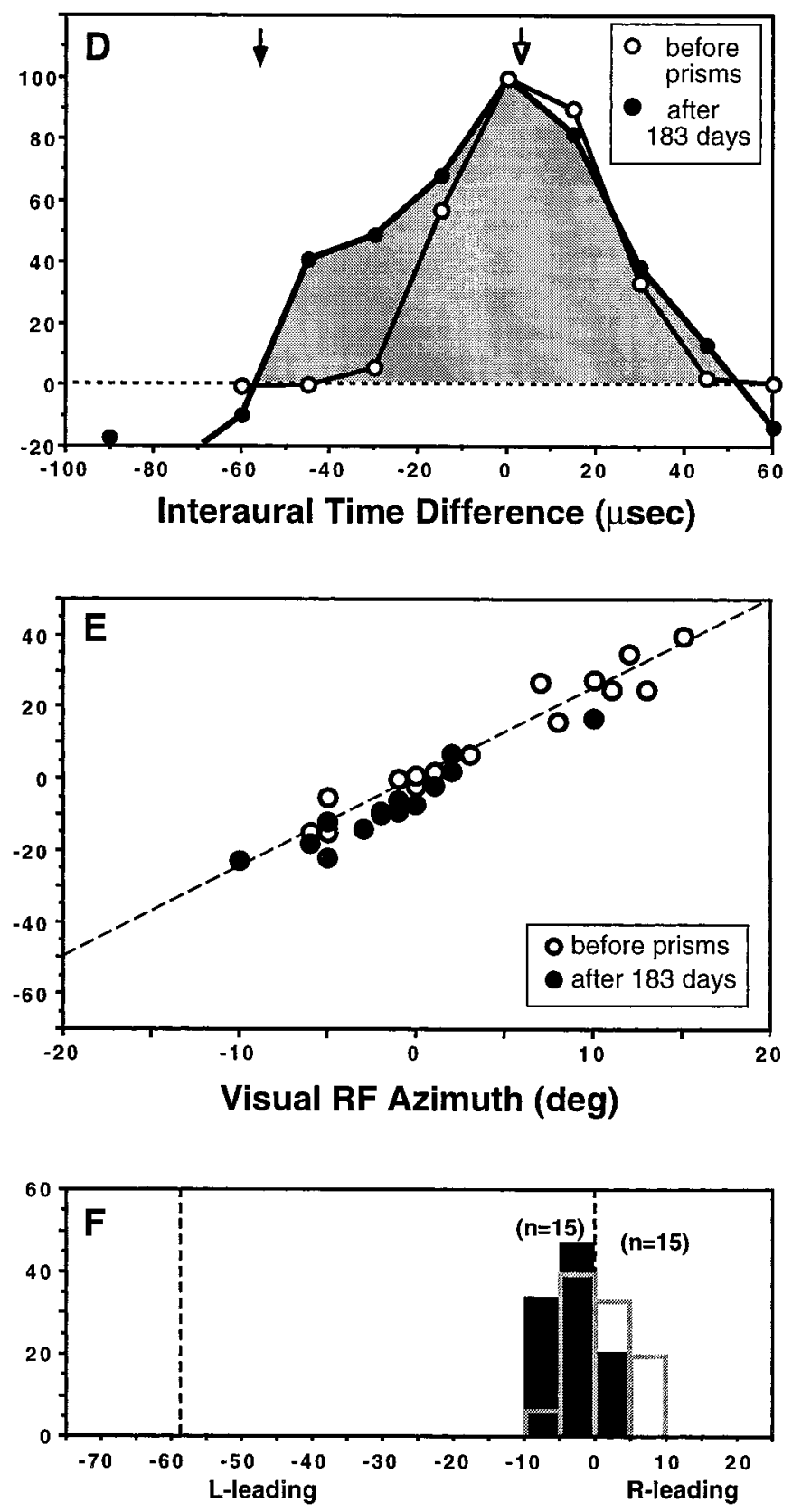

Best ITD Relative to Predicted ( $\mu \mathrm{sec})$

Figure 1. Effects of prism experience on ITD tuning of tectal units in a juvenile and an adult owl. $A$, ITD tuning before prism experience ( $\bigcirc)$ and after $28 \mathrm{~d}$ of prism experience $($ ) for an owl that was equipped with prisms at $88 \mathrm{~d}$ of age. Measurements were made at single tectal sites that had matched, frontally located VRFs. The best ITD measured before prisms were mounted was close to the value of ITD corresponding with the location of the VRF for the site (open arrow). The best ITD after $28 \mathrm{~d}$ of prism experience was shifted toward the value of ITD corresponding with the optically displaced VRF ( filled arrow). B, Best ITD as a function of VRF location for recordings made at 13 tectal sites before prisms were mounted $(O)$ and at 13 sites after $28 \mathrm{~d}$ of prism experience $(\bullet)$. The line indicates the normal relationship between best ITD and VRF azimuth determined from previous studies (see Materials and Methods). C, Differences between the measured values of best ITD and normal values predicted from VRF locations for all sites before prisms were mounted (open bars) and after $28 \mathrm{~d}$ of prism experience (solid bars). The vertical dashed lines indicate the ITD values corresponding to no adjustment $(0 \mu \mathrm{sec})$ or the maximum predicted adjustment $(57 \mu \mathrm{sec}) . D-F$, ITD tuning from the tectum of an adult owl that was equipped with prisms at $>1$ year of age. Measurements were made immediately before prisms were mounted and after $183 \mathrm{~d}$ of prism experience. Conventions are as in $A-C$. 
Figure 2. Time course of changes in ITD tuning after mounting of prisms. For owls 21 and 98, the data points represent the best ITD for single tectal sites that were measured repeatedly using chronically implanted electrodes. For the other owls, points reflect the average value of best ITD relative to the normal value predicted by VRF location sampled at multiple tectal sites. Positive values indicate shifts of tuning in the adaptive direction; a value of $0 \mu \mathrm{sec}$ indicates normal tuning and +57 $\mu \mathrm{sec}$ indicates the maximum expected shift in best ITD. The first point for each owl represents the mean best ITD relative to normal measured immediately before mounting of prisms. For owl 21, this value could not be measured and is therefore plotted as $0 \mu \mathrm{sec}$, the expected value (shaded circle). Owl Ad222 was at least 1 year old when prisms were mounted, but its exact age is not known; the time axis for this bird is therefore only approximate. At the top of the plot are indicated the approximate ages of various developmental events. The eyes first open at $\sim 10-12 \mathrm{~d}$ of age, although the ocular media remains cloudy until 16-18 d of age, and the eyes do not achieve final adult alignment until $\sim 45 \mathrm{~d}$ of age (Knudsen, 1989). The width of the skull and the feathers of the facial ruff reach adult size at $\sim 40 \mathrm{~d}$ of age (Haresign and Moiseff, 1988; Knudsen et al., 1984a). Owls begin to fly for the first time at $\sim 60 \mathrm{~d}$ of age (Bunn et al., 1982). Owls become capable of breeding at $\sim 200 \mathrm{~d}$ of age (E. I. Knudsen, personal observation).

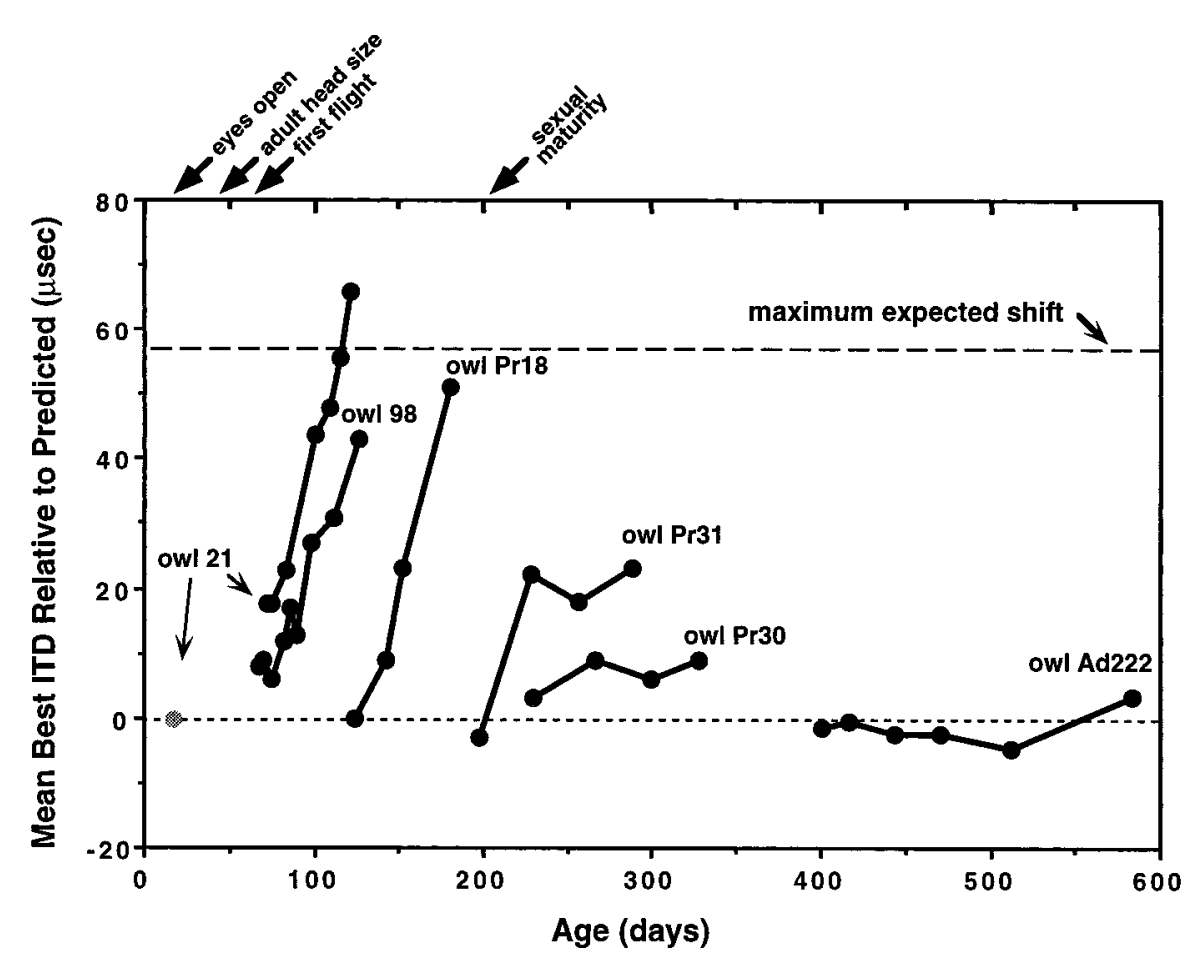

In contrast to the owl equipped with prisms at $88 \mathrm{~d}$ of age, a second owl (Ad222), which was equipped with R23 $3^{\circ}$ prisms as an adult (older than 1 year), showed essentially no change in ITD tuning with prism experience. Figure $1 D(\bigcirc)$ shows the ITD tuning measured at a recording site in the rostral tectum of this owl immediately before it was equipped with prisms. The best ITD was $4 \mu \mathrm{sec}$ right-ear leading, close to the normal value of 3 $\mu$ sec right-ear leading (open arrow) predicted from the location of the VRF of the site (R1 $\left.{ }^{\circ} \mathrm{az},-6^{\circ} \mathrm{el}\right)$. After $183 \mathrm{~d}$ of prism experience, the ITD tuning recorded in the tectum at a site with a matched VRF location $\left(\mathrm{R} 1^{\circ} \mathrm{az},-5^{\circ} \mathrm{el}\right)$ was relatively unchanged (Fig. $1 D, \boldsymbol{O}$ ), with a best ITD of $2 \mu$ sec left-ear leading. The relationship between best ITD and VRF azimuth before prism experience $(\bigcirc)$ and after $183 \mathrm{~d}$ of prism experience $(O)$ is summarized in Figure 1E,F. Before prisms were mounted, values of best ITD at each tectal site were close to the normal predicted value, with a mean difference of $1 \mu$ sec right-ear leading. After $183 \mathrm{~d}$ of prism experience, values of best ITD remained close to normal, with a mean difference of only $4 \mu$ sec left-ear leading. Thus, in this owl, despite a much longer period of altered vision than that experienced by the younger owl (183 vs $28 \mathrm{~d}$ ), there was a greatly reduced influence of visual experience on the tectal representation of ITD.

The time course of changes in ITD tuning after alteration of visual experience was measured in several owls. As observed in a previous study (Brainard and Knudsen, 1995), some units exhibited broad or double-peaked ITD tuning curves during the period when ITD tuning was shifting in response to prism experience. For these units, best ITDs represented the midpoint between the most left-ear leading and right-ear leading values of ITD that elicited half-maximal responses (see Materials and Methods). Figure 2 shows examples of the progression of changes in ITD tuning in the tecta of five owls that were equipped with prisms at varying ages. Each data point represents either the shift in ITD tuning measured with a chronic electrode at a single tectal site (owls 21 and 98) or the average shift in ITD tuning for a large number of recording sites in the tectum (owls Pr18, Pr31, Pr30, and Ad222). Owl 21 was equipped with prisms at $17 \mathrm{~d}$ of age, but chronic recordings were not begun until $68 \mathrm{~d}$ of age, after the skull had reached adult size and had hardened. For this owl, ITD tuning before prisms were mounted was not measured but is presumed to have been close to the normal value of $0 \mu \mathrm{sec}$ (Fig. 2 , shaded circle). For all of the other owls, the first data point shown is based on recordings that were made immediately before prisms were mounted. The progression of ITD tuning in owl 21 was typical of that described previously for owls equipped with prisms in the first few weeks of life: large prism-induced shifts in ITD tuning occurred only after $\sim 60 \mathrm{~d}$ of age (despite prolonged previous exposure to prisms), indicating that there may be a developmental delay before the nervous system becomes competent to respond adaptively to altered vision (Brainard and Knudsen, 1995). After $68 \mathrm{~d}$ of age, when recordings from this owl were begun, there was a rapid and systematic shift in ITD tuning that progressed at a rate of $\sim 1 \mu \mathrm{sec} / \mathrm{d}$. Owls 98 and Pr18 had L23 ${ }^{\circ}$ prisms mounted at 68 and $124 \mathrm{~d}$ of age, respectively. In contrast to what occurred in owls that had prisms mounted at younger ages, in these owls there was no apparent delay between the mounting of prisms and the initiation of changes in ITD tuning. ITD tuning shifted by $\sim 1 \mu \mathrm{sec} / \mathrm{d}$ during the period of most rapid change, and after $\sim 2$ months of prism experience, shifts in ITD tuning approached the maximum expected value of $57 \mu \mathrm{sec}$. Owl Pr31, which was equipped with prisms at $197 \mathrm{~d}$ of age, showed a significant shift in ITD tuning over the first $30 \mathrm{~d}$ of prism experience, but this shift, of $\sim 23 \mu \mathrm{sec}$, was smaller than that observed in owls equipped with prisms at younger ages and did not increase over the subsequent 2 months. Owl Pr30, equipped with prisms only slightly later, at $230 \mathrm{~d}$ of age, showed even less change in ITD tuning over several months of prism experience. Likewise, owl Ad222, equipped with prisms at $>1$ year of age, exhibited little or no change in ITD tuning over a period of 6 


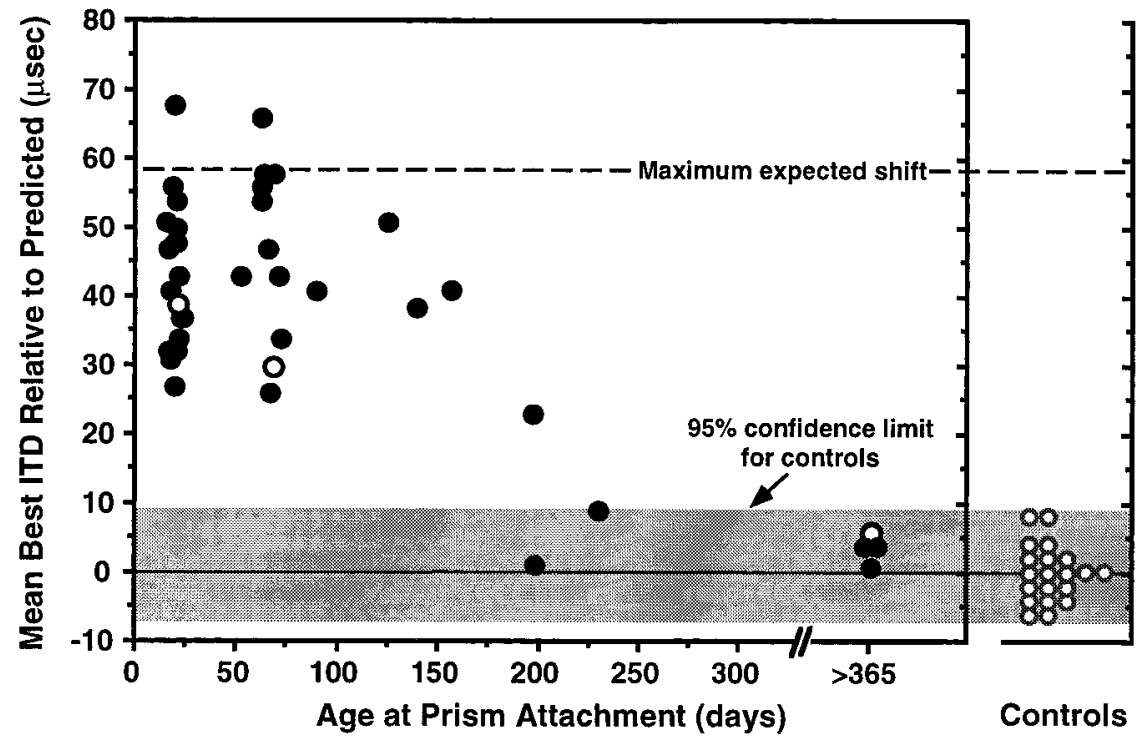

Figure 3. Shift in ITD tuning in the tectum as a function of the age at which owls were equipped with prisms. Each data point reflects the mean shift in best ITD for an individual owl after at least 2 months of prism experience. The data are based on both chronic recordings and tectal sampling. Positive values indicate shifts in the adaptive direction. Open symbols represent data from owls that exhibited auditory thresholds that were elevated relative to normal by 20-40 dB. Data from 20 normal adult owls are plotted for comparison. For the control owls, positive values indicate mean best ITDs that were more right-ear leading than predicted from the locations of VRFs. months of prism experience. Thus, it is apparent that the influence of altered visual experience declined with the age at which prisms were mounted.

The final magnitude of visually guided changes in ITD tuning for all 39 owls is shown as a function of the age at which the owls were equipped with prisms in Figure 3. Each data point represents the shift in tectal ITD tuning determined after at least 2 months of prism experience. On the basis of the observed time course of visually guided changes in ITD tuning (Fig. 2), this should have been adequate time to observe most of the changes in ITD tuning that were to occur. As documented in Table 1 and Figure 3, the magnitude of adjustment varied greatly, over a 2.5 -fold range, for young owls $(<70 \mathrm{~d}$ old $)$ that were exposed to the same environmental conditions. Clearly, there were factors that govern the plasticity of this system that were not under experimental control, such as the social, emotional, and genetic characteristics of the individuals. Despite this high degree of variability in adjustment magnitude in the young owls, however, there was a clear and dramatic loss of plasticity with age (Fig. 3). Under the conditions of our experiments, large visually guided changes in ITD tuning were limited to a sensitive period that ended at $\sim 200 \mathrm{~d}$ of age.

For the owls that were equipped with prisms as adults, there was a tendency for the mean best ITD to be shifted in the adaptive direction. The magnitude of this shift, however, was small. For the owl equipped with prisms at $230 \mathrm{~d}$ of age there was a mean shift of $9 \mu \mathrm{sec}$, and for the four owls equipped with prisms at $>365 \mathrm{~d}$ of age mean shifts in best ITD ranged from 1 to $6 \mu \mathrm{sec}$. Although these shifts in mean best ITD were all in the adaptive direction, they did not differ significantly from the distribution of misalignments found in control owls (control distribution shown in Fig. 3). Hence, on the basis of measurements of best ITD there was not a significant influence of altered visual experience on the tectal representation of space for owls older than $\sim 200 \mathrm{~d}$ of age.

The best ITD for a unit is based only on the range of ITD values for which responses exceed $50 \%$ of the maximum. Hence, best ITD is insensitive to various potential changes in ITD tuning. For example, in a previous study it was found that during early stages of visually guided changes in ITD tuning there could be two peaks in ITD tuning curves: one peak corresponding to the normally predicted best ITD and a second peak correspond- ing to the best ITD predicted from the optically displaced VRF (Brainard and Knudsen, 1995). Such secondary peaks do not influence the value of best ITD until they exceed $50 \%$ of the primary peak. Therefore, for the adult owls in this study that showed no significant changes in mean best ITD after altered visual experience, it remained possible that there were, nevertheless, more subtle changes in tuning curve shapes.

To look for subtle influences of prism experience on the ITD tuning of tectal units in the adult owls, we constructed population tuning curves (see Materials and Methods) for the final recording sessions for the five owls that were equipped with prisms at $>230$ d of age (Fig. 4). Our expectation was that we might find small secondary response peaks at values of ITD close to the value of ITD predicted from the optically displaced VRFs. This was not the case. For all five owls, the population tuning curves after 60-187 d of prism experience had single peaks centered near 0 $\mu \mathrm{sec}$, with little or no response at $\pm 57 \mu \mathrm{sec}$. In every case there was evidence of a small adaptive adjustment in ITD tuning, suggested by shifts or asymmetries in the flanks of the population tuning curves. However, on the whole, the population tuning curves revealed little beyond what was apparent from the examination of best ITDs.

\section{ITD tuning can shift alternately in both directions during the sensitive period}

A shift of ITD tuning in one direction did not prevent a subsequent shift of ITD tuning in the opposite direction in a juvenile owl. Figure 5 summarizes the shifts in ITD tuning for owl Pr18 that was equipped first with $\mathrm{R} 23^{\circ}$ prisms at $88 \mathrm{~d}$ of age and subsequently with $\mathrm{L} 23^{\circ}$ prisms at $124 \mathrm{~d}$ of age. Before prisms were mounted, the mean shift in best ITD relative to normal predicted values was $1 \pm 3 \mu \mathrm{sec}$ (open bars). At $116 \mathrm{~d}$ of age, after $28 \mathrm{~d}$ of prism experience, the mean best ITD relative to normal had shifted to $41 \pm 6 \mu \mathrm{sec}$ left-ear leading (solid bars). The R23 prisms were then removed and $8 \mathrm{~d}$ later $\mathrm{L} 23^{\circ}$ prisms were mounted. After $56 \mathrm{~d}$ of experience with these prisms, at $180 \mathrm{~d}$ of age, the tectum was remapped, and the mean best ITD relative to normal was $51 \pm 14 \mu \mathrm{sec}$ right-ear leading (striped bars). Thus, for this owl, the initial leftward shift in ITD tuning did not prevent a subsequent large rightward shift in ITD tuning. 

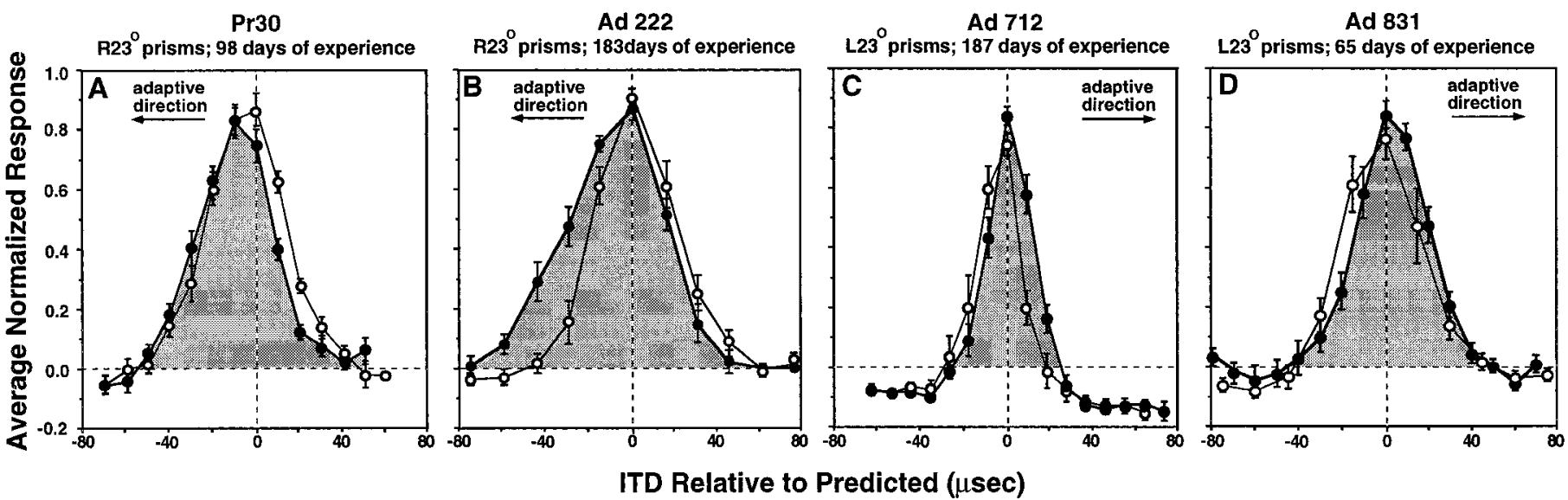

Figure 4. Effect of prism experience on population ITD tuning curves in four adult owls. Each population ITD tuning curve (see Materials and Methods) was based on ITD tuning curves measured at 13-18 sites sampled either before $(\bigcirc)$ or after $(\bullet)$ a long period of prism experience (indicated above each graph). Error bars represent SEM. Owls Pr30 and Ad222 experienced R23 prisms; owls Ad712 and Ad831 experienced L23 ${ }^{\circ}$ prisms. The arrow indicates the direction of adaptive shift for each owl.

\section{Owl Pr18}

A

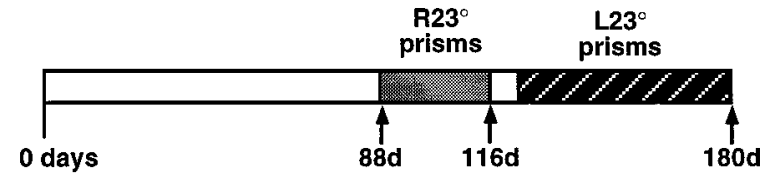

B

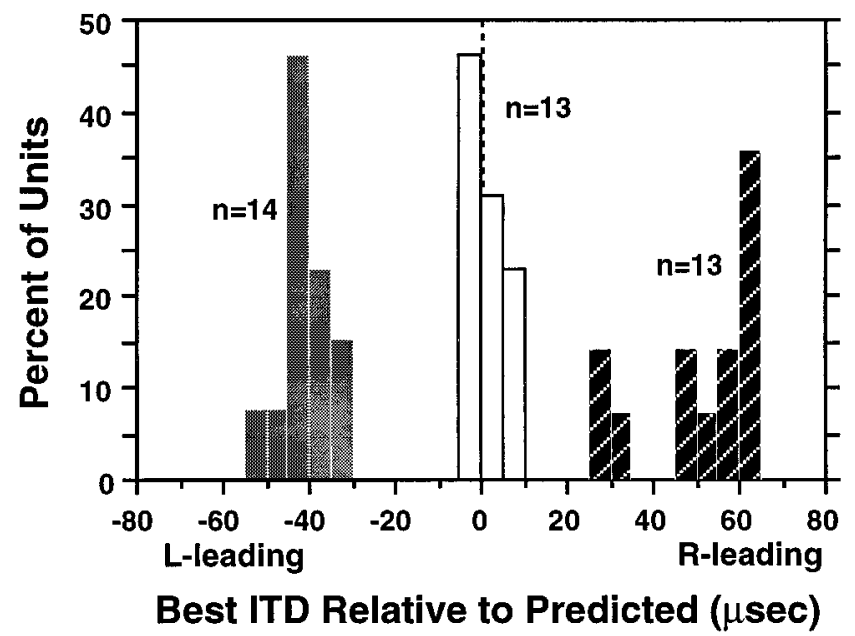

Figure 5. During the sensitive period, ITD tuning could be alternately shifted in both directions in the tectum of an individual owl. $A$, The timeline indicates the ages at which prisms were mounted and measurements were made. $B$, Histograms indicate the distribution of best ITDs relative to predicted normal for recording sites tested before prism experience ( $88 \mathrm{~d}$; open bars), after $28 \mathrm{~d}$ of experience with $\mathrm{R} 23^{\circ}$ prisms (116 d; solid bars), and after $56 \mathrm{~d}$ with L23 ${ }^{\circ}$ prisms (180 d; striped bars).

\section{Auditory thresholds increased in some owls}

Units in the tecta of some owls exhibited large increases in auditory thresholds during the study. In the most extreme cases, thresholds were elevated by $50 \mathrm{~dB}$ or more relative to normal values. We were unable to determine the cause of these increases in threshold. However, they occurred with greater frequency in older owls ( $>1$ year) than in younger ones, and often were associated with a change in chronic conditions, such as a new home cage or spectacle frames mounted in front of the eyes. Increases in thresholds were observed both in control owls and in owls subjected to altered vision. For prism-reared owls that exhibited increases in thresholds, these often occurred in the first weeks after prisms were mounted, but could occur as much as 5 months later. Moreover, increases in thresholds were not always permanent. In several cases, thresholds that had become elevated reverted to normal values in subsequent experiments without any obvious correlation with experimental manipulations.

It is possible that these increases in threshold resulted from stress. However, in the absence of a clear explanation of this phenomenon, we simply note here that it occurred and that data from these owls were treated in the following way. Three owls exhibited elevated thresholds during initial control recordings and were excluded from further study. Three owls exhibited sufficiently elevated thresholds after mounting of prisms that accurate ITD measurements could not be made, and they also were excluded from the study. Three other owls exhibited thresholds that were elevated by at least $20 \mathrm{~dB}$ in one or more recording sessions. Because it was possible to obtain accurate ITD tuning measurements from these owls despite their elevated thresholds, data from them are included but are indicated in Figure 3 by open symbols.

\section{The capacity to recover a normal space map is retained throughout life}

The capacity for normal visual experience to restore normal alignment between the auditory and visual maps of space in the optic tectum was assessed in 11 prism-reared owls (Table 1). Each owl was initially equipped with prismatic spectacles between 13 and $64 \mathrm{~d}$ of age. After 2 or more months of prism experience, electrophysiological recordings were used to asses the tectal map of auditory space and to confirm that, consistent with previous observations, the auditory map was displaced relative to the visual map. Prisms were then removed from these owls at ages ranging from 108 to $1208 \mathrm{~d}$, and subsequent changes in the auditory space map were assessed. In owls of all ages, the auditory map recovered normal alignment with the visual map.

Figure 6 illustrates the recovery of normal ITD tuning after restoration of normal vision to three prism-reared owls $(21,28$, and 17). These owls were equipped with prisms early in life and wore them continuously until they were removed at ages of 121 


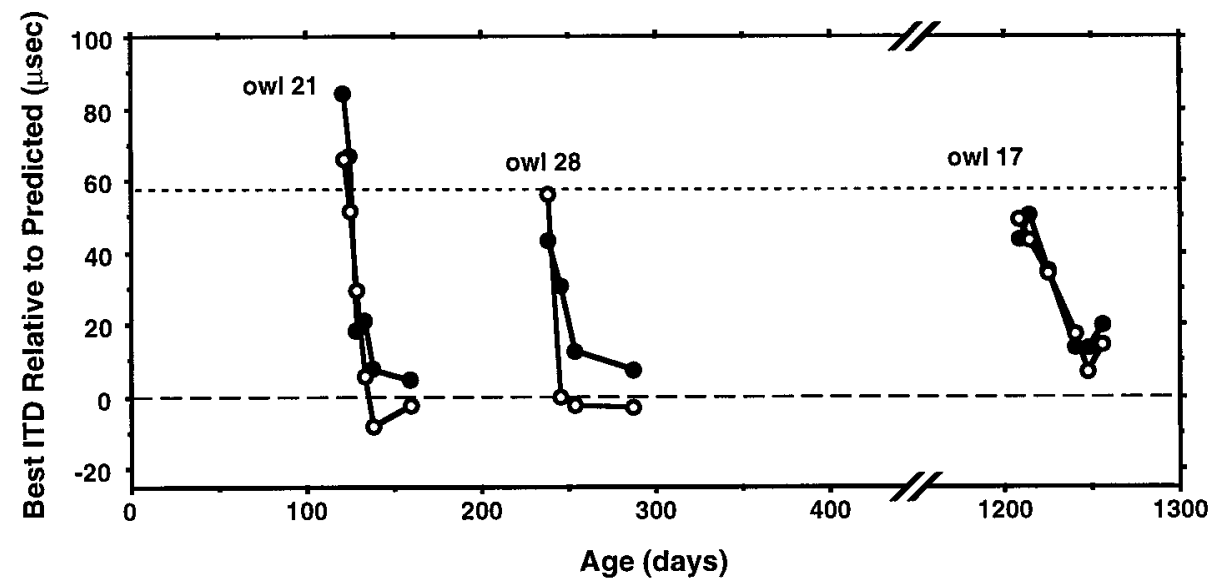

Figure 6. Time course of adjustment to normal ITD tuning after restoration of normal vision for three prism-reared owls. Changes in ITD tuning were followed at two tectal sites in each owl using chronic recording electrodes. Data from the two sites are distinguished by different symbol types. Each point represents the best ITD recorded at a single site in a given recording session. The first point of each series was collected immediately before prism removal.

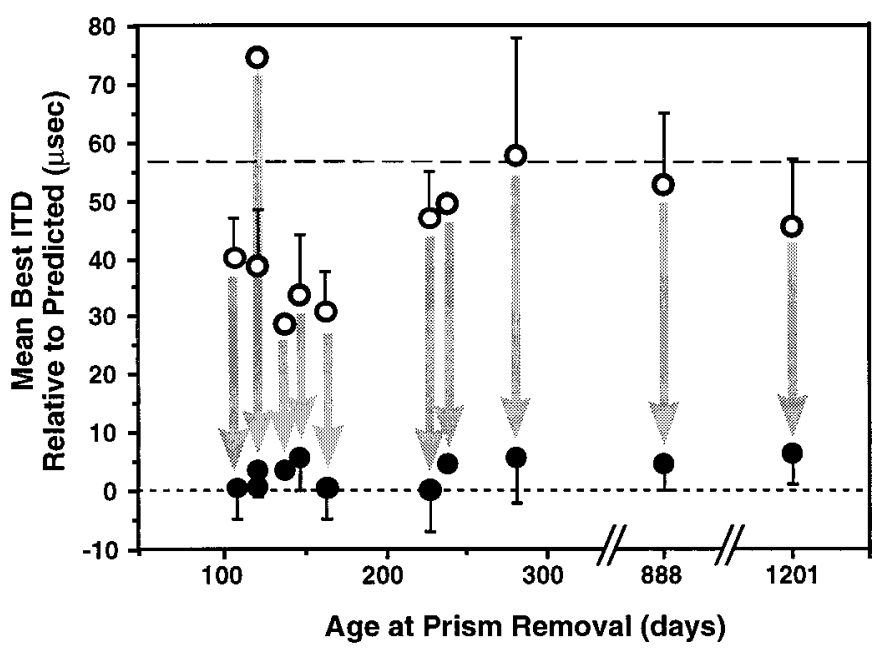

Figure 7. Recovery of normal ITD tuning as a function of the age at which prisms were removed. For each owl, a vertically aligned pair of points (connected by a shaded arrow) indicates the best ITD immediately before prism removal $(\bigcirc)$ and at least 1 month after prism removal $(\bullet)$. Mean best ITDs reflect measurements made with either chronic electrodes or by sampling the tectum at multiple sites. Error bars indicate 1 SD.

(owl 21), 238 (owl 28), and 1208 (owl 17) d of age, respectively. Shortly before removal of the prisms, the degree of shift in the tectum was measured, and two chronic recording electrodes were implanted in each owl so that subsequent changes in ITD tuning could be followed at single tectal sites. In all three owls, ITD tuning adjusted to the normal range within several weeks of prism removal. For owls 28 and 21, the rates of ITD tuning adjustment (averaged across the two recording sites in each owl) were $\sim 4-5$ $\mu \mathrm{sec} / \mathrm{d}$. For owl 17, ITD adjusted at a slower rate of $\sim 1 \mu \mathrm{sec} / \mathrm{d}$. Thus, there is some indication that the rate of ITD tuning recovery may decrease with age. However, these differences may simply reflect individual variability.

Figure 7 summarizes the adjustment of ITD tuning to normal as a function of the age at which normal vision was restored to 11 prism-reared owls. This figure combines data from owls for which the degree of shift in the tectal map of ITD was assessed by measuring populations of neurons before and after prism removal and from owls for which the degree of shift in the tectal map was assessed with chronic recordings from single tectal sites during periods preceding and after prism removal. Each arrow connects data from an individual owl representing tectal ITD tuning be- fore prism removal (Fig. 7, O) and after an extended period of normal visual experience after prism removal $(\bullet)$. The degree of recovery of a normal tectal map of ITD was comparable for owls of all ages, even for those that had prisms removed at $>2$ years of age. Thus, there was no indication of a sensitive period for the visually guided recovery of a normal map of ITD in the tectum.

\section{The experience required to restore a normal space map (and normal sound localization) changes with age}

The lack of a sensitive period for the recovery of a normal tectal map of ITD contrasts with the results from previous behavioral experiments in which the capacity for recovery of normal sound localization accuracy was found to be developmentally regulated (Fig. 8A) (Knudsen and Knudsen, 1990). In the current study, owls were housed in group aviaries where they could fly freely and interact with each other. In contrast, in the previous behavioral experiments, owls were housed in small individual cages (see Materials and Methods) where they could see and hear other owls but could not fly or interact directly with other owls. We hypothesized that the observed difference in the developmental regulation of neurally versus behaviorally assessed plasticity derived not from the different methods of assessment but from differences in the nature of the experience available to the owls. To test this hypothesis, we assessed the influence of different housing conditions on the capacity to recover a normal tectal map of ITD.

Consistent with the previous behavioral experiments, owls that were housed in small individual cages exhibited a sensitive period for the recovery of a normal tectal map of ITD. Figure $8 B$ summarizes changes in ITD tuning that occurred in prism-reared birds that were transferred to small cages and then had their prisms removed. Before removal of the prisms, the degree of shift in the tectal ITD map was assessed for each bird by measuring ITD tuning in a series of penetrations across the tectum. The maps of ITD in all of these birds were shifted significantly from normal, with mean shifts in best ITD that ranged from 26 to 47 $\mu \mathrm{sec}$. After the owls were transferred to individual cages and the prisms were removed, subsequent changes in ITD tuning were assessed periodically by resampling the tectum. For two owls that had prisms removed at 108 and $169 \mathrm{~d}$ of age, respectively, ITD tuning adjusted to normal over a period of days to weeks. In contrast, for three owls that had prisms removed at 228, 306, and $385 \mathrm{~d}$ of age, respectively, ITD tuning did not adjust to normal as long as the owls were housed in the small cages. Thus, for owls housed in small cages, there was a clear sensitive period for the recovery of a normal map of ITD that ended at $\sim 200 \mathrm{~d}$ of age, 
Individual Cage

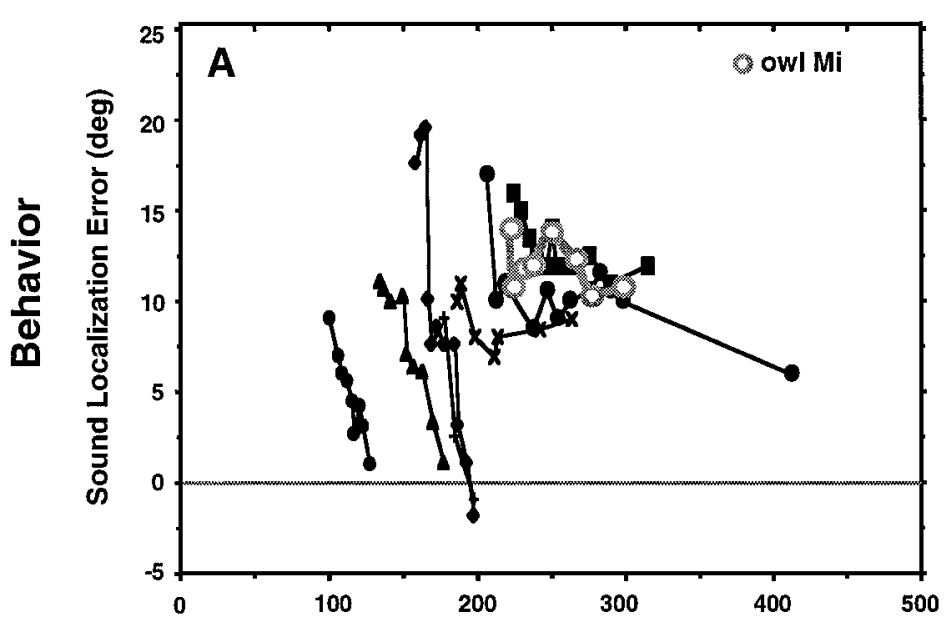

Large Aviary

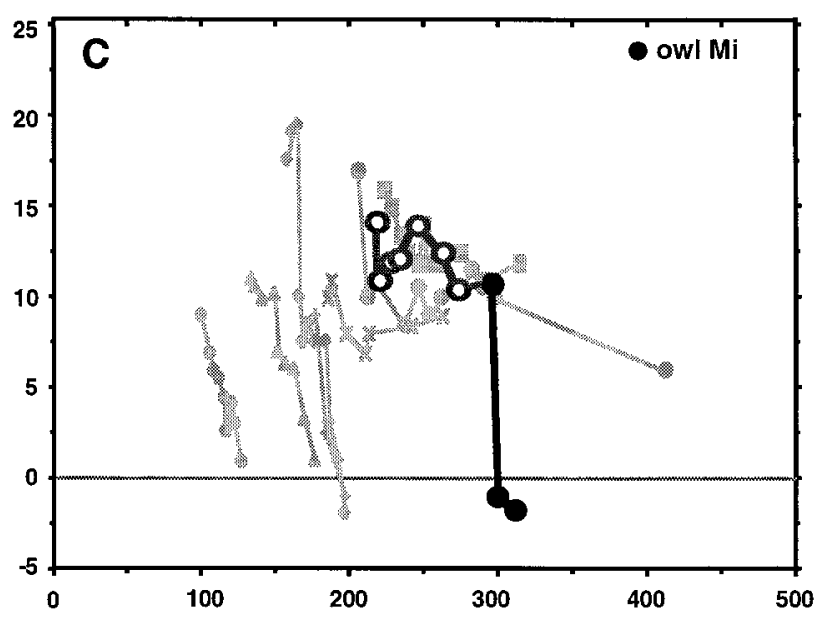

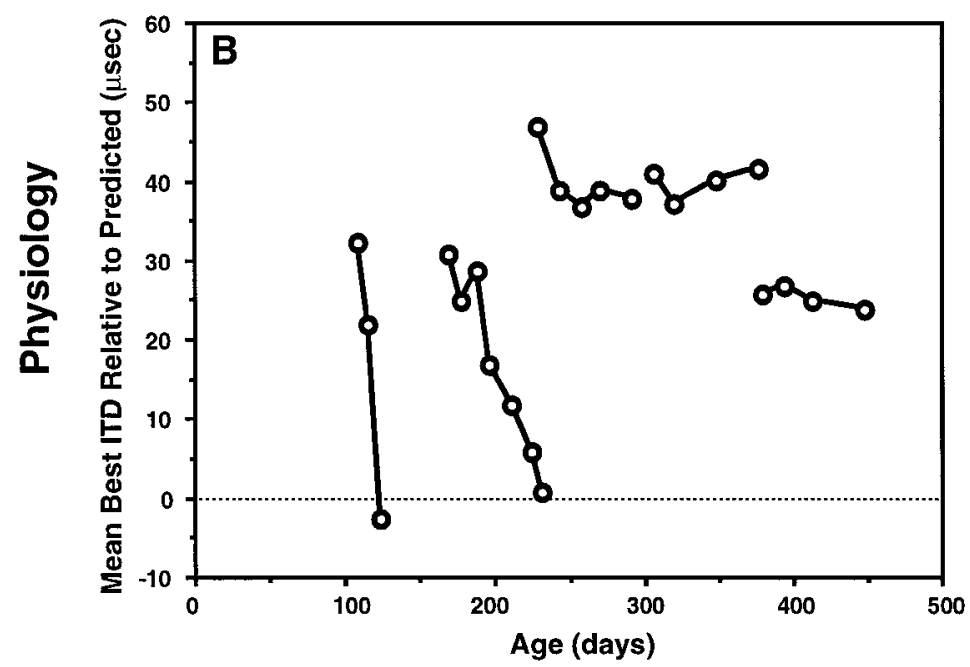

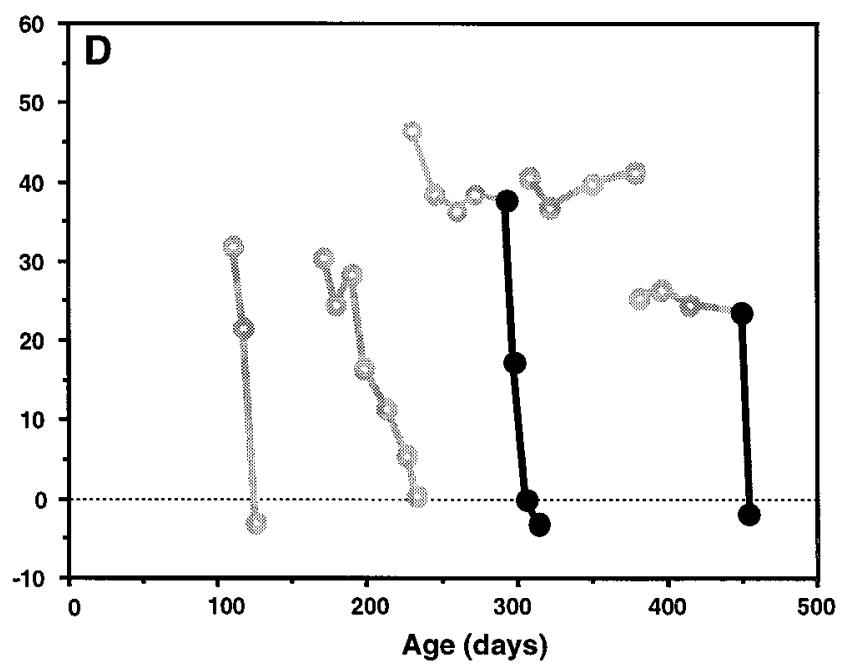

Figure 8. The influence of environmental richness on the capacity to adjust sound localization accuracy and the tectal map of ITD to normal after restoration of normal vision to prism-reared owls. $A$, Adjustment of sound localization accuracy by owls housed in individual cages. The open circles represent data from owl Mi measured in this study; the other data are from a previous study (Knudsen and Knudsen, 1990). Each point indicates the mean auditory orientation error for an individual owl in a single experimental session. The first point of each series indicates the error immediately before prism removal. When prisms were removed before $\sim 200 \mathrm{~d}$ of age, sound localization accuracy rapidly adjusted to normal; when prisms were removed later, sound localization accuracy did not adjust. $B$, Adjustment of ITD tuning in the tecta of owls housed in individual cages. Each point indicates the mean best ITD relative to normal for an individual owl. The first point of each series indicates the mean best ITD relative to normal immediately before prism removal. When prisms were removed before $200 \mathrm{~d}$ of age, ITD tuning adjusted to normal; when they were removed later, ITD tuning failed to adjust. $C$, Adjustment of sound localization accuracy to normal by an adult owl (owl Mi) that was housed in a large aviary. After prisms were removed at $219 \mathrm{~d}$ of age, the owl was first transferred to an individual cage $(\bigcirc)$ where it remained for $76 \mathrm{~d}$, exhibiting little adjustment of sound localization accuracy. At $295 \mathrm{~d}$ of age, the owl was transferred to a large aviary, and sound localization accuracy rapidly adjusted to normal (-). The data for owls housed in individual cages (from $A$ ) are shaded and included for comparison. $D$, Adjustment of ITD tuning in the tecta of adult owls that were housed in large aviaries. Two of the adult owls that had failed to adjust ITD tuning while housed in individual cages (shaded symbols, replotted from $B$ for comparison) were subsequently transferred to a large aviary, after which ITD tuning was adjusted to normal.

similar to that described for the recovery of accurate sound localization behavior (Fig. 8A) (Knudsen and Knudsen, 1990).

In the current study, normal ITD tuning was recovered in owls of any age that were housed in large aviaries (Fig. 7). As predicted by these results, two of the owls that failed to recover a normal ITD map when they were housed in small individual cages recovered normal ITD maps rapidly after being transferred to a large group aviary (Fig. $8 D$ ). These results confirm that the presence of a sensitive period for recovery of a normal ITD map after restoration of normal vision depends on the nature of the animal's experience; the map plasticity that was lost for owls housed in small cages was restored when the owls were transferred to the richer environment of the large aviaries.

These neurophysiological results imply that it should be possible to restore accurate sound localization behavior to adult prism-reared owls provided they are housed in a group flight room rather than in individual cages. We tested this idea in owl $\mathrm{Mi}$ that was raised with $\mathrm{R} 23^{\circ}$ prisms from 60 to $219 \mathrm{~d}$ of age (Fig. $8 C$, large circles). Before removal of the prisms, owl Mi oriented to sounds with a mean rightward error of $14^{\circ}$ degrees, indicating that it had adjusted its auditory orienting behavior in response to the chronically displaced visual field. At 219 d of age, the prisms were 
A

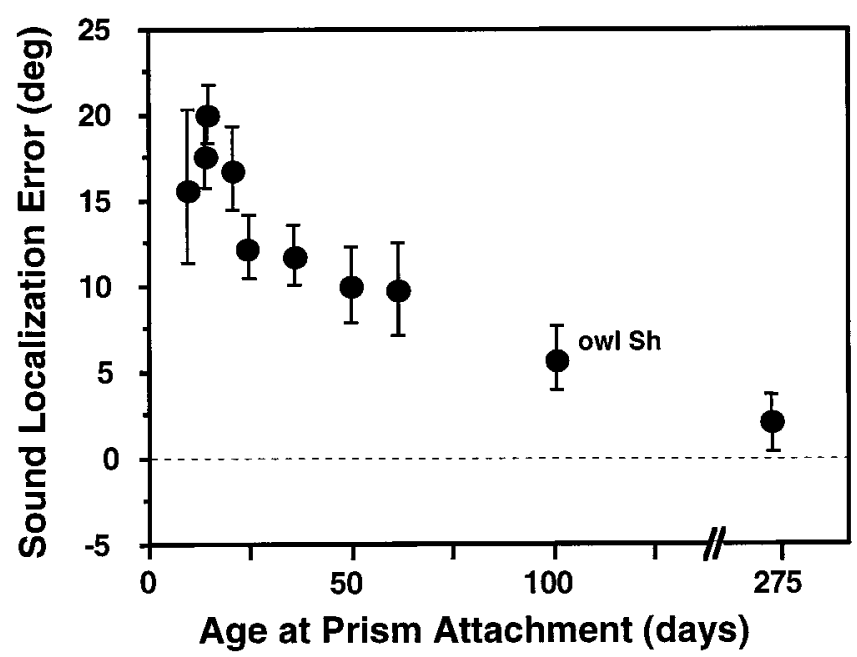

B Large Aviary

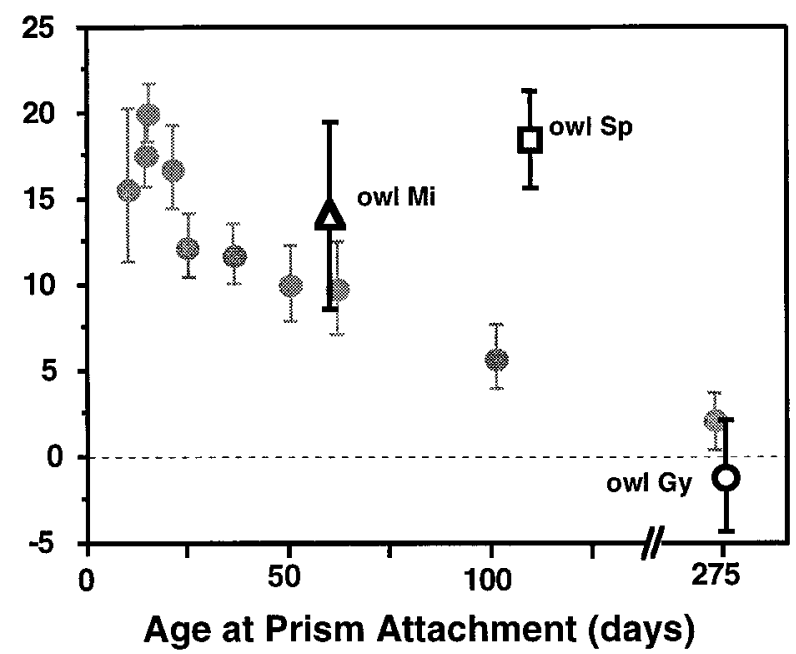

Figure 9. The influence of environmental richness on the sensitive period for the adjustment of sound localization accuracy in response to prism experience. Each data point represents the mean $( \pm \mathrm{SD})$ auditory orientation error measured for an individual owl after at least $60 \mathrm{~d}$ of experience with $23^{\circ}$ prisms; positive errors indicate shifts in the adaptive direction. $A$, These data are from a previous study (Knudsen and Knudsen, 1990) and show the effect of prism experience on sound localization accuracy for owls housed in individual cages. $B$, The open symbols represent data from three owls measured in this study and show the adjustment of sound localization accuracy for owls housed in large aviaries. The data from $A$ are shaded and plotted for comparison. The data from owl $S p(\square)$ indicate adjustment of sound localization accuracy at an age when little adjustment occurred in owls housed in individual cages (compare with owl Sh in $A$ ). No adjustment occurred in the adult owl, owl Gy (O), although it was housed in a large aviary.

removed, and the owl was transferred to an individual cage. Consistent with the previous behavioral experiments conducted using such cages (Knudsen and Knudsen, 1990), there was little reduction in the owl's average sound localization error over the next 2 months; after $76 \mathrm{~d}$ in the individual cage, the average auditory orientation error remained at $11^{\circ}$, and there was no apparent trend for a decrease in error (Fig. $8 A, \bigcirc$ ). The owl was then transferred to a flight aviary that adjoined a group aviary (see Materials and Methods). Five days later, when the owl was next tested, the auditory orientation error was gone (Fig. $8 C, \mathbf{\bullet}$ ). Thus, for recovery of normal sound localization accuracy, as for recovery of a normal tectal space map, a decrease in adjustment with age (i.e., a sensitive period) reflects inadequate experience available to the owl.

\section{Enriched conditions extend the sensitive period for altered visual experience to change sound localization behavior}

The remaining discrepancy between the behavioral results published previously and the neurophysiological results reported here is the age at which the sensitive period for altered visual experience to shift the auditory space map draws to a close. The behavioral results indicated a decrease in the range of auditory orientation adjustment by $60 \mathrm{~d}$ of age and only adult ranges of adjustment by $100 \mathrm{~d}$ of age (Fig. 9A) (Knudsen and Knudsen, 1990). In contrast, the neurophysiological results reported here indicate that large adjustments in the tectal auditory space map can occur up until $\sim 200 \mathrm{~d}$ of age (Fig. 3).

To test the hypothesis that the nature of the experience (i.e., small cage vs large aviary) is responsible for this discrepancy, $\mathrm{R} 23^{\circ}$ prisms were mounted on a 109-d-old owl (owl Sp), and the owl was placed in the flight room that adjoined a group aviary. Before the prisms were mounted, owl Sp oriented to sounds with an error of $0^{\circ} \pm 2$. After $68 \mathrm{~d}$ of prism experience, its orientation error was $18^{\circ} \pm 3$ (Fig. $9 B, \square$ ). The magnitude of this behavioral adjustment contrasts sharply with the $6^{\circ} \pm 2$ adjustment measured for owl Sh in the previous study after $75 \mathrm{~d}$ in an individual cage (Fig. 9A). The nearly complete behavioral adjustment of owl $\mathrm{Sp}$ is consistent with the current neurophysiological results (Fig. 3) and supports the conclusion that a rich environment is required to reveal the full capacity for adjustment.

To determine whether the plasticity of sound localization behavior does indeed decline with age even under the enriched conditions of the large aviary, we mounted $\mathrm{R} 23^{\circ}$ prisms on a 276-d-old owl (owl Gy) and placed it in the flight cage adjoining the group aviary. Before the prisms were mounted, the auditory orientation error of the owl was $0^{\circ} \pm 3$. After $79 \mathrm{~d}$ of prism experience, its orientation error was unchanged: L2 \pm 4 (Fig. 9B, $\bigcirc)$. Thus, by $276 \mathrm{~d}$ of age, the capacity for behavioral adjustment (as for neurophysiological adjustment) (Fig. 3) in response to displaced vision became severely restricted, even under these enriched conditions.

\section{DISCUSSION}

This study investigated the developmental regulation of plasticity in the auditory space processing pathway of the barn owl using two reciprocal sensory manipulations. (1) Normally reared owls were exposed to abnormal relationships between sound localization cues and locations in the visual field, and (2) prism-reared owls were exposed to normal relationships between sound localization cues and locations in the visual field. These manipulations were performed under two different sets of environmental conditions. (1) Some owls were housed in large aviaries where they could fly and interact with each other, and (2) other owls were housed in small cages where they could see and hear each other but could not interact directly or fly.

The capacity for plasticity depended strongly on both the nature of the manipulation that was used to elicit changes and the richness of the environment that was provided to the animal. 


\begin{tabular}{|c|c|c|}
\hline & Shift with prism experience (normal owls) & Recovery after prism removal (prism-reared owls) \\
\hline Small individual cage & $\begin{array}{l}\text { Up to } \mathbf{7 0 ~ d} \\
\text { Behavior: Knudsen and Knudsen (1990) } \\
\text { Physiology: not tested }\end{array}$ & $\begin{array}{l}\text { Up to } 200 \text { d } \\
\text { Behavior: Knudsen and Knudsen (1990); this study (Fig. 8) } \\
\text { Physiology: this study (Fig. 8) }\end{array}$ \\
\hline Large group aviary & $\begin{array}{l}\text { Up to } 200 \text { d } \\
\text { Behavior: this study (Fig. 9) } \\
\text { Physiology: this study (Fig. 3) }\end{array}$ & $\begin{array}{l}\text { Open-ended } \\
\text { Behavior: this study (Fig. 8) } \\
\text { Physiology: this study (Figs. 7, 8) }\end{array}$ \\
\hline
\end{tabular}

When the visual manipulation was held constant, the timing of sensitive periods depended on whether the owls were housed in small individual cages or large group aviaries. Likewise, when environmental conditions were held constant, the timing of sensitive periods depended on whether normally reared owls were subjected to abnormal visual experience or prism-reared owls were exposed to normal visual experience.

\section{Sensitive periods for the calibration of the sound localization pathway}

Sensitive periods in the development of the midbrain space processing pathway and sound localization behavior are summarized in Table 2. The values in Table 2 are the approximate ages at which plasticity in response to each combination of sensory manipulation and environmental condition was lost. In every case where there are both neurophysiological and behavioral data, there is close agreement between them.

The sensitive periods that have been observed can be summarized as follows. The period during which normal owls respond adaptively to prismatic displacement of the visual field ends at $\sim 70 \mathrm{~d}$ of age when owls are housed in individual cages. In contrast, this period does not end until $\sim 200 \mathrm{~d}$ of age when owls are housed in group flight rooms. The period during which prism-reared owls recover to normal after restoration of normal visual experience ends at $\sim 200 \mathrm{~d}$ of age when they are housed in small cages, but extends throughout life when they are housed in group flight rooms.

Sensitive periods in the development of sound localization and the tectal space map in the owl have also been characterized in response to chronic monaural occlusion (Knudsen et al., 1984a,b; Knudsen, 1985). Like prism-rearing, monaural occlusion disrupts the normal correspondences between sound localization cues and locations in space (Knudsen, 1985). Sensitive periods were characterized using the small cages described in this study. Under these conditions, the sensitive period for adjustments away from normal closed at $\sim 60 \mathrm{~d}$ of age, and the sensitive period for recovery to normal after restoration of normal hearing closed at $\sim 200 \mathrm{~d}$ of age. Thus, although adaptation to altered vision and to altered hearing may involve different mechanisms (Knudsen and Mogdans, 1992; Mogdans and Knudsen, 1994), adjustments to both manipulations are nevertheless limited to comparable sensitive periods. This similarity suggests that if the sensitive periods revealed by monaural occlusion were tested in owls housed in large aviaries, they would extend much later in development as was observed here for prism-rearing.

The data from both prism-rearing and monaural occlusion suggest that owls undergo biological changes at $\sim 60-70 \mathrm{~d}$ of age and again at $\sim 200 \mathrm{~d}$ of age that alter the nature of the experience that is required to induce large-scale changes in the sound local- ization pathway. Several developmental events correlate at least approximately with these ages.

First, the head and external ears (facial ruff) of the barn owl do not achieve adult size until the owl is almost 2 months old (Knudsen et al., 1984a; Haresign and Moiseff, 1988). These features determine the correspondences between sound localization cues and spatial locations experienced by an owl. Hence, the spatial interpretation of sound localization cues change during the first 2 months of life. If there are costs associated with maintaining plasticity in the sound localization pathway, it therefore would be adaptive to limit the maximal capacity for plasticity to this first 2 month period.

Second, at $\sim 2$ months of age owls begin to leave the nest and fly (Bunn et al., 1982). Attempts to fly to bimodal targets might provide a quality of sensory experience particularly salient for calibration of the sound localization pathway, because sound localization by owls is of primary importance during hunting, when both auditory and visual cues are used to navigate toward prey. Although it is clear that young owls $(<70 \mathrm{~d})$ can adjust sound localization without flight (Fig. 8), as owls reach the age of fledging they may begin to rely heavily on the sorts of feedback derived from flight to targets. In this case, owls housed in small cages may be deprived of appropriate experience to drive plastic changes after the age of fledging, whereas those housed in large aviaries are not.

Finally, at $\sim 200 \mathrm{~d}$ of age owls become capable of breeding, although the exact age for initial courtship behavior depends on seasonal cues (E. I. Knudsen, personal observation). Changes in hormonal status associated with sexual maturation might influence the capacity for plasticity. Sex steroids such as testosterone and estrogen have widespread and diverse influences on the nervous system. Furthermore, in various species, changes in hormone levels have been correlated with changes in the capacity for behavioral plasticity and learning (Korsia and Bottjer, 1983; Marler et al., 1988; Bottjer and Hewer, 1992; Hudson, 1993; Sherwin, 1997).

\section{The influence of environmental conditions on sensitive periods}

Sensitive periods both for adjustments away from normal and for recovery to normal were strikingly extended when owls were housed in large group aviaries versus in small individual cages (Table 2; Figs. 8, 9). Two factors may have contributed to this difference in plasticity. First, superior bimodal (auditory-visual) experience may have been available in the group aviary. For example, the more populated group aviary presumably provided quantitatively more stimulation to each owl. Moreover, the opportunity to fly to acoustic targets may have provided a qualitatively different (and better) instructive signal for driving plastic 
changes (as discussed above). Second, a more general enabling of plasticity may have been promoted by the richer social and sensory environment of the group aviary. For example, interacting with other birds and flying to targets may have influenced hormonal, attentional, or motivational systems that modulate the capacity for plasticity.

Other studies have also suggested that the timing of sensitive periods depends on the richness of the experience available to the animal. For example, the sensitive period during which sparrows can learn song from the playback of recorded sparrow song ends at $\sim 50 \mathrm{~d}$ of age (Marler, 1970; Baptista and Petrinovich, 1986). However, if birds are tutored by a live adult bird rather than by a recorded song, the sensitive period does not end until later (Baptista and Petrinovich, 1986) (but also see Baptista and Gaunt, 1997; Nelson, 1997). Similarly, the sensitive period during which filial imprinting of ducklings normally occurs may be extended if they are placed in an environment in which exposure to novel stimuli is enforced (Bolhuis, 1991).

It is apparent, then, that the timing and even the existence (this study) of sensitive periods for nervous system plasticity may depend on the nature of the sensory experience that is available to the animal. This point is important not only for the experimental study of developmental plasticity and its regulation, but it also may relate to the prospects for the amelioration of developmental disorders in humans. For example, recent studies indicate that disorders of cognitive development, in which subnormal language ability remains refractory to improvement in various therapeutic settings, may show dramatic improvement in response to experience with particularly salient training stimuli (Merzenich et al., 1996; Tallal et al., 1996).

\section{Possible mechanisms underlying adjustment to, and recovery from, abnormal visual experience}

For owls housed either in small cages or in large aviaries, the capacity for abnormal visual experience to alter the representation of auditory spatial cues away from normal was lost before the capacity for normal visual experience to cause abnormal representations to shift back to normal. Indeed, for prism-reared owls housed in group aviaries, the capacity to recover a normal ITD map was never lost, although the sensitive period for adjustments away from normal closed at $\sim 200 \mathrm{~d}$ of age. This capacity for recovery to normal was retained into adulthood even for owls that were equipped with prisms when their eyes first opened, at an age when both the visual and auditory systems were immature. Hence, the marked asymmetry is unlikely to be attributable to an early, experience-driven consolidation of a normal pattern of connectivity.

The asymmetry in the capacity of owls to adjust to prisms versus recovery from prisms might be attributable, in part, to differences in the quality of visual experience with and without prisms, respectively. Two lines of evidence, however, argue against this explanation. First, owls younger than $200 \mathrm{~d}$ old adjusted readily in response to prism experience (Fig. 2). Hence, the quality of vision through the prisms was adequate to drive auditory adjustments consistently in these animals. In contrast, owls just a few months older exhibited almost no auditory adjustment after much longer periods of prism experience ( $>6$ months) (Fig. 4), although prism-reared owls of the same ages adjusted rapidly to normal after prism removal (Figs. 6, 7). It seems unlikely that the quantitative difference in the quality of vision with and without prisms could account for this qualitative difference in adjustment capacity.
Second, a recent study found that owls that had previously adjusted ITD tuning as a consequence of prism experience as juveniles were able to readjust ITD tuning in the same direction as adults when exposed to the same prismatic displacement (Knudsen, 1998). These adult owls, however, were not able to adjust ITD tuning in the opposite, novel direction when exposed to oppositely directed prisms. In this paradigm, vision through the prisms was adequate to drive ITD tuning adjustments in the previously learned direction but not in the novel direction.

A more likely basis for the asymmetry in the capacity to adjust in response to abnormal versus normal visual experience is an innate bias for the nervous system to form approximately normal connections in anticipation of normal experience. An innate bias toward normal connections is consistent with previous observations that a nearly normal auditory map can be established in the tectum of blind-reared owls despite a lack of visual cues (Knudsen et al., 1991) and can be established initially in the tectum of prism-reared owls despite contradictory visual cues (Brainard and Knudsen, 1995).

A possible physical substrate for such an innate bias is suggested by previous cellular studies of plasticity in the sound localization pathway. It is known that the visually guided changes in the tectal auditory space map can be accounted for by plasticity at the next earlier stage in the auditory pathway: the external nucleus of the inferior colliculus (ICX) (Brainard and Knudsen, 1993). Changes in neural tuning in the ICX, in turn, correlate with experience-dependent remodeling of a topographic projection from the map of ITD in the central nucleus of the inferior colliculus (ICC) to the ICX. In normal adult owls, this topographic projection connects points in the ICC to points in the ICX that represent similar values of ITD (Wagner et al., 1987; Feldman and Knudsen, 1997). In prism-reared owls, a novel topographic projection is elaborated that is appropriate to account for the shifted map of ITD in the ICX (Feldman and Knudsen, 1997). However, in these owls the normal topographic projection is also retained (Feldman and Knudsen, 1997). Thus, the anatomical substrate is present in prism-reared owls for representing both normal and shifted representations of ITD in the ICX, although only one representation is usually expressed at any one time.

These observations suggest that establishment of abnormal ITD tuning may require the elaboration of novel anatomical projections, whereas recovery of normal ITD tuning may require only the reactivation of (retained) normal connections via mechanisms of synaptic regulation. According to this model, the asymmetry in the sensitive periods for adjustments away from normal versus recovery to normal reflects a difference in the requirements of these two processes for axonal growth.

\section{REFERENCES}

Baptista LF, Gaunt SLL (1997) Social interaction and development in birds. In: Social influences on vocal development (Snowdon CT, Hausberger M, eds), pp 23-40. Cambridge: Cambridge UP.

Baptista L, Petrinovich L (1986) Song development in the whitecrowned sparrow: social factors and sex differences. Anim Behav 34:1359-1371.

Bolhuis JJ (1991) Mechanisms of avian imprinting: a review. Biol Rev 66:303-345.

Bottjer SW, Hewer SJ (1992) Castration and antisteroid treatment impair vocal learning in male zebra finches. J Neurobiol 23:337-353.

Brainard MS, Knudsen EI (1993) Experience-dependent plasticity in the inferior colliculus: a site for visual calibration of the neural representation of auditory space in the barn owl. J Neurosci 13:4589-4608.

Brainard MS, Knudsen EI (1995) Dynamics of visually guided auditory 
plasticity in the optic tectum of the barn owl. J Neurophysiol 73:595-614.

Bunn D, Warburton A, Wilson R (1982) The barn owl. Vermillion, SD: Buteo.

Clarkson R, Eimas P, Marean G (1989) Speech perception in children with histories of recurrent otitis media. J Acoust Soc Am 85:926-933.

Clayton NS (1989) The effects of cross-fostering on selective song learning in estrildid finches. Behavior 109:163-175.

Eales LA (1985) Song learning in zebra finches: some effects of song model availability on what is learnt and when. Anim Behav 33:1293-1300.

Eales LA (1987) Song learning in female-raised zebra finches: another look at the sensitive phase. Anim Behav 35:1356-1365.

Feldman DE, Knudsen EI (1997) An anatomical basis for visual calibration of the auditory space map in the barn owl's midbrain. J Neurosci 17:6820-6837.

Haresign T, Moiseff A (1988) Early growth and development of the common barn-owl's facial ruff. Auk 105:699-705.

Hudson R (1993) Olfactory imprinting. Curr Biol 3:548-552.

Immelmann K (1972) Sexual imprinting in birds. Adv Study Beh 4:147-174.

Knudsen EI (1982) Auditory and visual maps of space in the optic tectum of the owl. J Neurosci 2:1177-1194.

Knudsen EI (1985) Experience alters spatial tuning of auditory units in the optic tectum during a sensitive period in the barn owl. J Neurosci 5:3094-3109.

Knudsen EI (1989) Fused binocular vision is required for development of proper eye alignment in barn owls. Vis Neurosci 2:35-40.

Knudsen EI (1998) Capacity for plasticity in the adult owl auditory system expanded by juvenile experience. Science 279:1531-1533.

Knudsen EI, Brainard MS (1991) Visual instruction of the neural map of auditory space in the developing optic tectum. Science 253:85-87.

Knudsen EI, Knudsen PF (1989a) Vision calibrates sound localization in developing barn owls. J Neurosci 9:3306-3313.

Knudsen EI, Knudsen PF (1989b) Visuomotor adaptation to displacing prisms by adult and baby barn owls. J Neurosci 9:3297-3305.

Knudsen EI, Knudsen PF (1990) Sensitive and critical periods for visual calibration of sound localization by barn owls. J Neurosci 63:131-149.

Knudsen EI, Mogdans J (1992) Vision-independent adjustment of unit tuning to sound localization cues in response to monaural occlusion in developing owl tectum. J Neurosci 12:3485-3493.

Knudsen EI, Esterly SD, du Lac S (1991) Stretched and upside-down maps of auditory space in the optic tectum of blind-reared owls: acoustic basis and behavioral correlates. J Neurosci 11:1727-1747.

Knudsen EI, Esterly SD, Knudsen PF (1984a) Monaural occlusion alters sound localization during a sensitive period in the barn owl. J Neurosci 4:1001-1011.

Knudsen EI, Knudsen PF, Esterly SD (1984b) A critical period for the recovery of sound localization accuracy following monaural occlusion in the barn owl. J Neurosci 4:1012-1020.

Korsia S, Bottjer SW (1983) Chronic testosterone treatment impairs vocal learning in male zebra finches during a restricted period of development. J Neurosci 11:2362-2371.

Kuhl P (1991) Perception, cognition, and the ontogenetic and phylogenetic emergence of human speech. In: Plasticity of development $(\mathrm{Br}$ auth S, Hall W, Dooling R, eds), pp 73-106. Cambridge, MA: MIT.

Leiderman P (1981) Human mother-infant social bonding: is there a sensitive phase? In: Behavioral development (Immelmann K, Barlow G, Petrinovich L, Main M, eds), pp 454-468. Cambridge, UK: Cambridge UP.

Marler P (1970) A comparative approach to vocal learning: song development in white-crowned sparrows. J Comp Physiol Psychol 71:1-25.

Marler P, Peters S, Ball GF, Dufty AM, Wingfield JC (1988) The role of sex steroids in the acquisition and production of birdsong. Nature 336:770-772.

Merzenich MM, Jenkins WM, Johnston P, Schreiner C, Miller SL, Tallal P (1996) Temporal processing deficits of language-learning impaired children ameliorated by training. Science 271:77-81.

Mogdans J, Knudsen EI (1994) A site of auditory plasticity in the brainstem (VLVp) of the owl revealed by early monaural occlusion. J Neurophysiol 72:2875-2891.

Moiseff A, Konishi M (1981) Neuronal and behavioral sensitivity to binaural time differences in the owl. J Neurosci 1:40-48.

Needleman H (1977) Effects of hearing loss from early recurrent otitis media on speech and language development. In: Hearing loss in children (Jaffe B, ed), pp 640-649. Baltimore: University Park.

Nelson DA (1997) Social interaction and sensitive phases for song learning. In: Social influences on vocal development (Snowdon CT, Hausberger M, eds), pp 7-22. Cambridge, UK: Cambridge UP.

Olsen JF, Knudsen EI, Esterly SD (1989) Neural maps of interaural time and intensity differences in the optic tectum of the barn owl. J Neurosci 9:2591-2605.

Ruben R, Rapin I (1980) Plasticity of the developing auditory system. Ann Otol Rhinol Laryngol 89:303-311.

Sherwin BB (1997) Estrogen effects on cognition in menopausal women. Neurology 1997:S21-26.

Steinbach MJ, Money KE (1973) Eye movements of the owl. Vision Res 13:889-891.

Tallal P, Miller SL, Bedi G, Byma G, Wang X, Nagarajan SS, Schreiner C, Jenkins WM, Merzenich MM (1996) Language comprehension in language-learning impaired children improved with acoustically modified speech. Science 271:81-84.

Wagner H, Takahashi T, Konishi M (1987) Representation of interaural time difference in the central nucleus of the barn owl's inferior colliculus. J Neurosci 7:3105-3116. 